\title{
Tuning Proton Conductivity in Alkali Metal Phosphonocarboxylates by Cation Size-Induced and Water-Facilitated Proton Transfer Pathways
}

Montse Bazaga-García, ${ }^{\dagger}$ Maria Papadaki, ${ }^{\S}$ Rosario M. P. Colodrero, ${ }^{\dagger}$ Pascual Olivera-Pastor, ${ }^{\dagger}$ Enrique R. Losilla, ${ }^{\dagger}$ Belén Nieto-Ortega, ${ }^{\dagger}$ Miguel Ángel G. Aranda, ${ }^{\dagger}, \|$ Duane Choquesillo-Lazarte, ${ }^{\perp}$ Aurelio Cabeza, ${ }^{* \dagger}$ and Konstantinos D. Demadis*, $\S^{\varnothing}$

${ }^{\dagger}$ Departamento de Química Inorgánica, and ${ }^{\ddagger}$ Departamento de Química Física, Universidad de Málaga, Campus Teatinos s/n, Málaga-29071, Spain

${ }^{\S}$ Crystal Engineering, Growth and Design Laboratory, Department of Chemistry, University of Crete, Voutes Campus, Crete, GR-71003, Greece

"ALBA Synchrotron, Ctra., BP1413 km 3.3, Cerdanyola del Vallès, Barcelona-08290, Spain

${ }^{\perp}$ Laboratorio de Estudios Cristalográficos, IACT, CSIC-Universidad de Granada, Granada-18100, Spain

Supporting Information

ABSTRACT: The structural and functional chemistry of a family of alkali-metal ions with racemic $R, S$-hydroxyphosphonoacetate (M-HPAA; $\mathrm{M}=\mathrm{Li}, \mathrm{Na}, \mathrm{K}, \mathrm{Cs}$ ) are reported. Crystal structures were determined by X-ray data $\left(\mathrm{Li}^{+}\right.$, powder diffraction following an $\mathrm{ab}$ initio methodology; $\mathrm{Na}^{+}, \mathrm{K}^{+}, \mathrm{Cs}^{+}$, single crystal). A gradual increase in dimensionality directly proportional to the alkali ionic radius was observed. $\left[\mathrm{Li}_{3}\left(\mathrm{OOCCH}(\mathrm{OH}) \mathrm{PO}_{3}\right)\right.$ $\left.\left(\mathrm{H}_{2} \mathrm{O}\right)_{4}\right] \cdot \mathrm{H}_{2} \mathrm{O}$ (Li-HPAA) shows a 1D framework built up by Li-ligand "slabs" with $\mathrm{Li}^{+}$in three different coordination environments (4-, 5-, and 6-coordinated). Na-HPAA, $\mathrm{Na}_{2}\left(\mathrm{OOCCH}(\mathrm{OH}) \mathrm{PO}_{3} \mathrm{H}\right)\left(\mathrm{H}_{2} \mathrm{O}\right)_{4}$, exhibits a pillared layered "house of cards" structure, while K-HPAA, $\mathrm{K}_{2}\left(\mathrm{OOCCH}(\mathrm{OH}) \mathrm{PO}_{3} \mathrm{H}\right)\left(\mathrm{H}_{2} \mathrm{O}\right)_{2}$, and Cs-HPAA, Cs(HOOCCH$(\mathrm{OH})$ $\left.\mathrm{PO}_{3} \mathrm{H}\right)$, typically present intricate $3 \mathrm{D}$ frameworks. Strong hydrogen-bonded networks are created even if no water is present, as is the case in Cs-HPAA. As a result, all compounds show proton conductivity in the range $3.5 \times 10^{-5} \mathrm{~S} \mathrm{~cm}^{-1}$ (Cs-HPAA) to $5.6 \times 10^{-3} \mathrm{~S}$ $\mathrm{cm}^{-1}$ (Na-HPAA) at $98 \% \mathrm{RH}$ and $\mathrm{T}=24{ }^{\circ} \mathrm{C}$. Differences in proton conduction

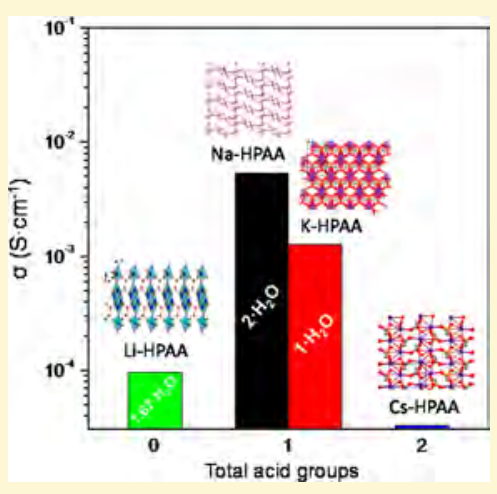
mechanisms, Grothuss $\left(\mathrm{Na}^{+}\right.$and $\left.\mathrm{Cs}^{+}\right)$or vehicular $\left(\mathrm{Li}^{+}\right.$and $\left.\mathrm{K}^{+}\right)$, are attributed to the different roles played by water molecules and/or proton transfer pathways between phosphonate and carboxylate groups of the ligand HPAA. Upon slow crystallization, partial enrichment in the $S$ enantiomer of the ligand is observed for Na-HPAA, while the Cs-HPAA is a chiral compound containing only the $S$ enantiomer.

\section{INTRODUCTION}

Metal-organic frameworks (MOFs) possess versatile structures that can be tunable for a broad range of applications, including gas separation and storage, catalysis, etc. ${ }^{1}$ Built from metalcentered secondary building units, linked together by the organic ligand, MOFs exhibit open frameworks containing accessible, functionalized, and highly uniform pores for performing a number of physicochemical processes inside cavities. Recently, focus on energy materials has attracted attention on the potential of MOF materials in developing high performance fuel cells, mainly in polymer electrolyte membrane fuel cells (PEMFCs). These systems require proton-conducting pathways, such as hydrogen-bonding networks, to accomplish proton transport. MOFs and related materials are promising candidates for membranes in PEMFCs because they usually contain water, acidic groups, and/or other functional groups amenable to $\mathrm{H}$-bonding interactions. ${ }^{2}$ Morever, the high crystallinity exhibited by MOFs is considered to be an advantage to establish structure-activity relationships by, for instance, visualization of well-defined H-bond networks inside the cavities. ${ }^{3}$ Up to now, several MOFs have been reported with measured conductivity values close to $10^{-2} \mathrm{~S} \mathrm{~cm}^{-1}$.

Metal phosphonates are MOF-type coordination polymers that also show remarkable inherent characteristics as proton conductors. ${ }^{5}$ Not only do they have acidic sites, but they also exhibit a certain degree of structural adaptability and pores filled with guest species $\left(\mathrm{H}_{2} \mathrm{O}, \mathrm{NH}_{4}^{+}\right.$, heterocycles, carboxylic acids, to mention a few) that act as proton carriers. ${ }^{5,6}$ Transition and rare-earth metal phosphonate chemistry has been substantially investigated in the past decades, and, as a result, some representative compounds have been found to exhibit relevant properties as proton conductors. ${ }^{5 \mathrm{~b}}$ Alkali-metal

Received: July 23, 2014

Revised: November 20, 2014

Published: December 20, 2014 
phosphonate chemistry, however, lags behind mainly due to the limited availability of structurally characterized compounds. Nevertheless, there are some examples in the literature that warrant a short presentation.

Lis has published a series of crystal structures of alkali metal ions with the ligand phosphonoacetic acid $\left(\mathrm{H}_{3} \mathrm{AP}\right.$, the number after the $\mathrm{H}$ denotes the acidic protons), $\mathrm{KH}_{2} \mathrm{AP} \cdot \mathrm{H}_{2} \mathrm{O}, \mathrm{LiH}_{2} \mathrm{AP}$, $\mathrm{NaH}_{2} \mathrm{AP} \cdot \mathrm{H}_{2} \mathrm{O}, \mathrm{K}_{2} \mathrm{HAP}, \mathrm{Na}_{2} \mathrm{HAP} \cdot 2 \mathrm{H}_{2} \mathrm{O}$, and $\mathrm{Na}_{3} \mathrm{AP} \cdot 10 \mathrm{H}_{2} \mathrm{O}$. These materials are prepared in aqueous solutions with the indicated stoichiometries. The alkali ion is found coordinated by the carboxylate and phosphonate oxygens and also by water molecules. Coordination numbers vary, depending on ionic radius, 8 for $\mathrm{K}^{+}, 4$ for $\mathrm{Li}^{+}$, and 6 for $\mathrm{Na}^{+}$.

Cheng and Lin determined the structure of a polymeric material containing $\mathrm{Li}^{+}$and the ligand ethylenediphosphonic acid, $\left(\left[\mathrm{Li}\left(\mathrm{C}_{2} \mathrm{H}_{7} \mathrm{O}_{6} \mathrm{P}_{2}\right)\right]_{n}\right) .{ }^{8}$ It is interesting to note that the tetrahedral $\mathrm{Li}^{+}$center is coordinated by the phosphoryl $(\mathrm{P}=\mathrm{O})$ oxygen and not by the deprotonated phosphonic acid moiety, $\mathrm{P}-\mathrm{O}^{-}$. Clearfield et al. determined the crystal structures of the ligand biphenylenebisphosphonate with the entire alkali metal series ( $\mathrm{Li}, \mathrm{Na}, \mathrm{K}, \mathrm{Rb}, \mathrm{Cs})$. All structures are pillared-layered, with the ligand playing the role of the pillar between $\mathrm{M} / \mathrm{O}$ layers. ${ }^{9}$ The major difference between the structures is the coordination numbers of the alkali metal centers: 4 for $\mathrm{Li}^{+}, 6$ for $\mathrm{Na}^{+}, 6$ for $\mathrm{K}^{+}, 7$ for $\mathrm{Rb}^{+}$, and 8 for $\mathrm{Cs}^{+}$. Other lithium phosphonates are the layered $\mathrm{Li}$-methylphosphonate $\mathrm{Li}$ $\left(\mathrm{CH}_{3} \mathrm{PO}_{3} \mathrm{H}\right)$, published by Mermer and Starynowicz, ${ }^{10}$ where the tetrahedral coordination of $\mathrm{Li}^{+}$is completed exclusively by phosphonate oxygens, and the mononuclear molecular complex $\mathrm{Li}\left(\mathrm{H}_{2} \mathrm{ALE}\right)\left(\mathrm{H}_{2} \mathrm{O}\right)_{2}{ }^{11}\left(\mathrm{H}_{4} \mathrm{ALE}=\right.$ alendronic acid, $\mathrm{H}_{2} \mathrm{~N}$ $\left.\left(\mathrm{CH}_{2}\right)_{3} \mathrm{C}(\mathrm{OH})\left(\mathrm{PO}_{3} \mathrm{H}_{2}\right)_{2}\right)$, which contains $\mathrm{Li}^{+}$ions in a tetrahedral coordination environment and a protonated amine group $\left(-\mathrm{NH}_{3}{ }^{+}\right)$. In general, Li-containing inorganic-organic frameworks are important for a number of reasons. First, such materials are "light" and can potentially display high gas storage capacity. ${ }^{12}$ There are examples in the literature where $\mathrm{Li}$ incorporation into the framework dramatically enhances gas storage capabilities. ${ }^{13}$ Second, there is intense interest in $\mathrm{Li}$ based rechargeable batteries. ${ }^{14}$ Recently, high proton conductivity was reported for crystalline polyelectrolytes, such as poly(ethylene oxide $)_{6} / \mathrm{LiXF}_{6}(\mathrm{X}=\mathrm{P}, \mathrm{As}, \mathrm{Sb}){ }^{15}$

Various Na-phosphonates have been reported, with $\mathrm{Na}^{+}$ showing invariably octahedral coordination. So, Aranda et al. used the tripodal ligand AMP (amino-tris(methylenephosphonic acid) $)$ to prepare $\mathrm{Na}_{2}\left[\left(\mathrm{HO}_{3} \mathrm{PCH}_{2}\right)_{3} \mathrm{NH}\right] \cdot 1.5 \mathrm{H}_{2} \mathrm{O}$ at low $\mathrm{pH} .{ }^{16}$ The structure was solved by ab initio methodology, and was found to be pillared-layered. Two of the phosphonate moieties of AMP are responsible for creating the 2D motif, whereas the third acts as a bridge between layers. Also, a pillared-layered structure was obtained for $\mathrm{Na}\left[\mathrm{H}_{3} \mathrm{bdp}\right], \mathrm{H}_{4}$ bdp $=1,4$-benzenediphosphonic acid, and reported by Ayi et al. ${ }^{17}$ The use of diphosphonic ligands, $\mathrm{H}_{4} \mathrm{~L}$ [zolendronic (ZOL), alendronic (ALE), pamidronic (PAM), and olpadronic (OLP)], leads to the zero-dimensional compound $\left[\mathrm{Na}\left(\mathrm{H}_{3} \mathrm{ZOL}\right)\right.$ $\left.\left(\mathrm{H}_{2} \mathrm{O}\right)_{3}\right] \cdot \mathrm{H}_{2} \mathrm{O}^{18}$ or $1 \mathrm{D}$ solids with different stoichiometries and water content. ${ }^{19-21}$ The crystal structures of the monodimensional solids are composed of chains that differ between them by the way in which the ligand, as zwitter ion, coordinates to $\mathrm{Na}^{+}$. Particularly interesting is the fact that the diphosphonate linker, in the disodium pamidronate, ${ }^{20}$ $\mathrm{Na}_{2}\left[\mathrm{H}_{2} \mathrm{PAM}\right] \cdot 5 \mathrm{H}_{2} \mathrm{O}$, acts as bidentate ligand with respect to one of the two crystallographically independent $\mathrm{Na}^{+}$. Another remarkable structural feature of these compounds is the existence of strong hydrogen bonds, providing both intraand interchain connectivity. Furthermore, the dehydrationrehydration process was found completely reversible in some compounds, provided that the temperature of decomposition was not exceeded. These structural characteristics are in principle interesting attributes to investigate the proton conductivity of alkali phosphonates.

Regarding $\mathrm{K}^{+}$or $\mathrm{Cs}^{+}$phosphonates, very few derivatives have been reported up to now. ${ }^{5 b}$ On the other hand, the entire series of alkali phosphites has been reported as a family of superprotonic anhydrous solid acids. These solids are unique in the sense that the protons themselves are the mobile species, in contrast with proton conducting polymeric electrolytes, which usually require water molecules to enable transport. ${ }^{22}$ Similarly, the high temperature phase of $\mathrm{Rb}\left(\mathrm{MePO}_{3} \mathrm{H}\right) \cdot 2 \mathrm{H}_{2} \mathrm{O}$ has been suggested as a promising candidate for proton conductivity. ${ }^{23}$

In this Article, we report the syntheses, structural characterization, and proton conductivity of a family of alkali metal carboxyphosphonates containing the ligand $R, S$-hydroxyphosphonoacetic acid (HPAA). The compounds, prepared by crystallization at room temperature, are the following: $\left[\mathrm{Li}_{3}\left(\mathrm{OOCCH}(\mathrm{OH}) \mathrm{PO}_{3}\right)\left(\mathrm{H}_{2} \mathrm{O}\right)_{4}\right] \cdot \mathrm{H}_{2} \mathrm{O}$ (Li-HPAA); $\left[\mathrm{Na}_{2}\left(\mathrm{OOCCH}(\mathrm{OH}) \mathrm{PO}_{3} \mathrm{H}\right)\left(\mathrm{H}_{2} \mathrm{O}\right)_{4}\right]$ (Na-HPAA); $\left[\mathrm{K}_{2}\left(\mathrm{OOCCH}(\mathrm{OH}) \mathrm{PO}_{3} \mathrm{H}\right)\left(\mathrm{H}_{2} \mathrm{O}\right)_{2}\right]$ (K-HPAA); [Cs$\left.\left(\mathrm{HOOCCH}(\mathrm{OH}) \mathrm{PO}_{3} \mathrm{H}\right)\right]$ (Cs-HPAA). There is a progressive increase in the dimensionality of the network, from 1D ( $\mathbf{L i}$ HPAA) through pillared-layered (Na-HPAA) to 3D (K-HPAA and Cs-HPAA). The structure-proton conductivity relationships are discussed on the basis of the possible pathways involved in proton conduction processes. Additionally, a chiral structure of compound Cs-HPAA is reported as an unusual example of ligand enantiomer enrichment ( $S$-configuration) from a simple crystallization procedure of a metal derivative of the racemic ligand $R, S$-HPAA.

\section{EXPERIMENTAL SECTION}

Reagents and Materials. The starting alkali metal salts and hydroxides were from commercial sources and used as received $\left(\mathrm{LiOH} \cdot \mathrm{H}_{2} \mathrm{O}, \mathrm{KOH}, \mathrm{CsCl}\right.$ were from Riedel-de Haen, and $\mathrm{NaOH}$ from Sigma-Aldrich). R,S-HPAA ( $68.5 \% \mathrm{w} / \mathrm{v}, 50 \% \mathrm{w} / \mathrm{w}$ aqueous solution) was from Biolabs, UK. Deionized (DI) water from a laboratory cation exchange column was used for all syntheses. Stock solutions of $\mathrm{HCl}$ and $\mathrm{NaOH}$ were used for $\mathrm{pH}$ adjustments.

Synthesis of Alkali Metal-HPAA Compounds. Li-HPAA, $\left[\mathrm{Li}_{3}\left(\mathrm{OOCCH}(\mathrm{OH}) \mathrm{PO}_{3}\right)\left(\mathrm{H}_{2} \mathrm{O}\right)_{4}\right] \cdot \mathrm{H}_{2} \mathrm{O}$. A volume of $0.5 \mathrm{~mL}(2.195$ mmol) from the concentrated HPAA solution $68.5 \% \mathrm{w} / \mathrm{v}$ is mixed with $20 \mathrm{~mL}$ of dimethylformamide (DMF). Next, $0.276 \mathrm{~g}$ (6.585 $\mathrm{mmol}$, 3-fold excess) of $\mathrm{LiOH} \cdot \mathrm{H}_{2} \mathrm{O}$ is separately dissolved in $30 \mathrm{~mL}$ of deionized (DI) water. The two solutions are then mixed under vigorous stirring, and the final (slightly turbid) solution is covered and left to stand at room temperature. After 7 days a microcrystalline precipitate forms. It is isolated by filtration, washed with acetone to remove traces of DMF (water must be avoided because the compound is soluble in it), and it is finally allowed to dry in air. Anal. Calcd for $\mathrm{Li}_{3} \mathrm{C}_{2} \mathrm{H}_{12} \mathrm{PO}_{11}$ : C, 9.10; $\mathrm{H}, 4.58$. Found: $\mathrm{C}, 8.66 ; \mathrm{H}, 4.43$.

$\mathrm{Na}-\mathrm{HPAA},\left[\mathrm{Na}_{2}\left(\mathrm{OOCCH}(\mathrm{OH}) \mathrm{PO}_{3} \mathrm{H}\right)\left(\mathrm{H}_{2} \mathrm{O}\right)_{4}\right]$. A volume of $0.2 \mathrm{~mL}$ (from the concentrated HPAA solution $68.5 \% \mathrm{w} / \mathrm{v}, 0.878 \mathrm{mmol}$ ) is diluted in DI water up to $25 \mathrm{~mL}$ volume. Next, $0.296 \mathrm{~g}(1.756 \mathrm{mmol})$ os solid $\mathrm{NaCl}$ is added to it. The solution is stirred until everything dissolves. The solution $\mathrm{pH}$ is 2.2 at that point. This clear colorless solution is left to stand at room temperature, while the solvent (DI water) is partially evaporated. After 4 days, a microcrystalline solid precipitates out. It is isolated by filtration, washed with DI water, and left to dry in air. Anal. Calcd for $\mathrm{C}_{2} \mathrm{H}_{11} \mathrm{Na}_{2} \mathrm{O}_{10} \mathrm{P}_{1}$ : C, 8.82; $\mathrm{H}, 4.07$. Found: C, 8.95; H, 3.87 . 
Table 1. Selected Crystallographic Data for M-HPAA ( $\mathrm{M}=\mathrm{Li}, \mathrm{Na}, \mathrm{K}$, and Cs) Compounds

\begin{tabular}{|c|c|c|c|c|}
\hline phase & Li-HPAA & Na-HPAA & K-HPAA & Cs-HPAA \\
\hline empirical formula & $\mathrm{C}_{2} \mathrm{H}_{12} \mathrm{Li}_{3} \mathrm{O}_{11} \mathrm{P}$ & $\mathrm{C}_{2} \mathrm{H}_{11} \mathrm{Na}_{2} \mathrm{O}_{10} \mathrm{P}$ & $\mathrm{C}_{4} \mathrm{H}_{14} \mathrm{~K}_{4} \mathrm{O}_{16} \mathrm{P}_{2}$ & $\mathrm{C}_{2} \mathrm{H}_{4} \mathrm{CsO}_{6} \mathrm{P}$ \\
\hline $\mathrm{FW}\left(\mathrm{g} \mathrm{mol}^{-1}\right)$ & 251.81 & 272.06 & 536.49 & 287.93 \\
\hline space group & $P \overline{1}$ & $P 2_{1} / c$ & $P n a 2_{1}$ & $P 2_{1} 2_{1} 2_{1}$ \\
\hline$\lambda(\AA)$ & 1.5406 & 0.71073 & 0.71073 & 1.54178 \\
\hline$a(\AA)$ & $5.80769(11)$ & $5.9296(6))$ & $30.895(3)$ & $5.1415(2)$ \\
\hline$b(\AA)$ & $7.00288(14)$ & $5.9066(5)$ & $5.8349(11)$ & $9.0028(3)$ \\
\hline$c(\AA)$ & $14.43082(29)$ & $28.136(3)$ & $9.6805(6)$ & $15.0537(5)$ \\
\hline$\alpha(\mathrm{deg})$ & $96.6474(15)$ & 90.0 & 90.0 & 90.0 \\
\hline$\beta(\operatorname{deg})$ & $93.8598(15)$ & $100.941(3)$ & 90.0 & 90.0 \\
\hline$\gamma(\operatorname{deg})$ & $112.4334(12)$ & 90.0 & 90.0 & 90.0 \\
\hline$V\left(\AA^{3}\right)$ & $534.859(21)$ & $967.52(16)$ & $1745.1(4)$ & $696.80(4)$ \\
\hline crystal size $(\mathrm{mm})$ & polycrystalline & $0.12 \times 0.10 \times 0.10$ & $0.10 \times 0.08 \times 0.06$ & $0.42 \times 0.32 \times 0.25$ \\
\hline$Z$ & 2 & 4 & 4 & 4 \\
\hline$V_{\text {at non-H }}\left(\AA^{3}\right.$ atom $\left.^{-1}\right)$ & 15.73 & 16.13 & 16.77 & 17.42 \\
\hline$\rho_{\text {calc }}\left(\mathrm{g} \mathrm{cm}^{-3}\right)$ & 1.563 & 1.868 & 2.043 & 2.745 \\
\hline $2 \theta$ range $(\mathrm{deg})$ & $4.00-100.00$ & $2.95-26.37$ & $2.48-25.02$ & $5.73-66.45$ \\
\hline data/restraints/parameters & $5266 / 21 / 110$ & $1990 / 2 / 200$ & $2957 / 1 / 241$ & $1224 / 0 / 92$ \\
\hline no. reflns & 1094 & 9743 & 8591 & 8413 \\
\hline ind reflns $[I>2 \sigma(I)]$ & & 1990 & 2957 & 1224 \\
\hline$R_{\mathrm{wp}}$ & 0.0696 & & & \\
\hline$R_{\mathrm{p}}$ & 0.0943 & & & \\
\hline$R_{\mathrm{F}}$ & 0.1242 & & & \\
\hline $\mathrm{GOF}, F^{2}$ & & 1.117 & 1.135 & 1.136 \\
\hline$R$ factor $[I>2 \sigma(I)]$ & & $\mathrm{R} 1^{a}=0.0436, \mathrm{wR} 2^{a}=0.1201$ & $\mathrm{R} 1^{a}=0.0503, \mathrm{wR}^{a}=0.1211$ & $\mathrm{R}^{a}=0.0516, \mathrm{wR} 2^{a}=0.1221$ \\
\hline$R$ factor (all data) & & $\mathrm{R} 1^{a}=0.0457, \mathrm{wR} 2^{a}=0.1218$ & $\mathrm{R} 1^{a}=0.0518, \mathrm{wR}^{a}=0.1240$ & $\mathrm{R} 1^{a}=0.0516, \mathrm{wR} 2^{a}=0.1221$ \\
\hline CCDC ref code & 986441 & 986442 & 986444 & 986443 \\
\hline
\end{tabular}

K-HPAA, $\left[\mathrm{K}_{2}\left(\mathrm{OOCCH}(\mathrm{OH}) \mathrm{PO}_{3} \mathrm{H}\right)\left(\mathrm{H}_{2} \mathrm{O}\right)_{2}\right]$. A volume of $0.5 \mathrm{~mL}$ (2.195 mmol) from the concentrated HPAA solution $68.5 \% \mathrm{w} / \mathrm{v}$ is mixed with $20 \mathrm{~mL}$ of DMF. Next, a quantity of $0.369 \mathrm{~g}(6.585 \mathrm{mmol})$ of $\mathrm{KOH}$ is separately dissolved in $10 \mathrm{~mL}$ of DI water. The two solutions are mixed under vigorous stirring, and the final (slightly turbid) solution is covered and left to stand at room temperature. After 7 days a microcrystalline precipitate forms. It is isolated by filtration, washed with acetone to remove traces of DMF (water must be avoided), and is finally left to dry in air. Anal. Calcd for $\mathrm{C}_{4} \mathrm{H}_{14} \mathrm{~K}_{4} \mathrm{O}_{16} \mathrm{P}_{2}$ : C, 8.95; H, 2.63. Found: C, 8.36; H, 2.43 .

Cs-HPAA, [Cs $\left.\left(\mathrm{HOOCCH}(\mathrm{OH}) \mathrm{PO}_{3} \mathrm{H}\right)\right]$. A volume of $0.1 \mathrm{~mL}$ (from the concentrated HPAA solution $68.5 \% \mathrm{w} / \mathrm{v}, 0.439 \mathrm{mmol}$ ) is diluted with DI water up to a volume of $75 \mathrm{~mL}$. Next, a quantity of $0.296 \mathrm{~g}(1.756$ $\mathrm{mmol}$ ) of solid $\mathrm{CsCl}$ is added to it. The solution is stirred until everything dissolves. The solution $\mathrm{pH}$ is 2.2 at that point. The clear colorless solution is left to stand at room temperature, while the solvent (DI water) is partially evaporated. After 4 days, a microcrystalline solid precipitates. It is isolated by filtration, washed with DI water, and is left to dry in air. Anal. Calcd for $\mathrm{C}_{2} \mathrm{H}_{4} \mathrm{O}_{6} \mathrm{PCs}$ : C, 8.34; $\mathrm{H}$, 1.40. Found: $\mathrm{C}, 8.36 ; \mathrm{H}, 1.46$. For circular dichroism experiments, this compound was also prepared by fast precipitation from $96 \%$ ethanol $(50 \mathrm{~mL})$. The powder X-ray diffraction patterns for powder Cs-HPAA obtained by slow crystallization and quick precipitation are in good agreement (Figure S-1, see Supporting Information) with the calculated pattern from the single-crystal data.

Instrumentation. The $\mathrm{pH}$-meter used was a wTw $\mathrm{pH} 315 \mathrm{i}$ setup, equipped with a SeTix 41 electrode. Elemental analyses (C, H, N) were measured on a Perkin-Elmer 240 analyzer. Thermogravimetric analysis (TGA) data were recorded on an SDT-Q600 analyzer from TA Instruments. The temperature varied from room temperature to $900{ }^{\circ} \mathrm{C}$ at a heating rate of $10{ }^{\circ} \mathrm{C} \mathrm{min}^{-1}$. Measurements were carried out on samples in open platinum crucibles under air flow. Water adsorption isotherms at $24^{\circ} \mathrm{C}$ were obtained on a VSTAR sorption analyzer commercialized by Quantachrome Corp. Before the adsorption analysis, the sample was outgassed at $24{ }^{\circ} \mathrm{C}$ for $30 \mathrm{~min}$. The selection of the $24{ }^{\circ} \mathrm{C}$ temperature for outgassing was selected to avoid any loss of the lattice water molecules. Infrared spectra were obtained with an ATR accessory (MIRacle ATR, PIKE Technologies, U.S.) coupled to FTIR spectrometer (FT/IR-4100, JASCO, Spain). All spectra were recorded in the $4000-600 \mathrm{~cm}^{-1}$ range at $4 \mathrm{~cm}^{-1}$ resolution, and 50 scans were accumulated.

Structural Determinations. Laboratory X-ray powder diffraction (XRPD) patterns were collected on a PANanalytical X'Pert Pro diffractometer. XRPD patterns corresponding to the single phases were autoindexed using the DICVOL06 program, ${ }^{24}$ and the space groups were derived from systematic extinctions. To minimize preferred orientation effects, the XRPD pattern of Li-HPAA was recorded in Debye-Scherrer transmission configuration (samples within rotating borosilicate glass capillaries of diameter of $0.5 \mathrm{~mm}$ ) by using a hybrid $\mathrm{Ge}(220)$ primary monochromator $\left(\mathrm{Cu} \mathrm{K} \alpha_{1}\right.$ radiation) and a X'Celerator detector. This X-ray pattern was recorded between 4 and $100^{\circ}(2 \theta)$, with a $0.017^{\circ}$ step size and an equivalent counting time of ca. $3000 \mathrm{~s} /$ step. Its crystal structure was solved following an ab initio methodology using the transmission patterns. The integrated intensities extracted with the program DAjust ${ }^{25}$ were introduced in the direct methods program XLENS. ${ }^{26}$ The starting framework model, containing almost the full content of the asymmetric unit, was derived from the interpretation of the electron density map computed with the set of refined phases with the highest combined figure of merit. The two missing $\mathrm{Li}$ atoms were localized by Fourier difference maps. The crystal structure was refined by the Rietveld method ${ }^{27}$ by using the GSAS package ${ }^{28}$ with soft constraints to maintain chemically reasonable geometries for the phosphonate, carbon chain, and carboxylic groups. The soft constraints were: $/ \mathrm{PO}_{3} \mathrm{C}_{1}$ tetrahedron/ $\mathrm{P}-\mathrm{O}[1.53(1) \AA], \mathrm{P}-\mathrm{C}_{1}[1.80(1) \AA], \mathrm{O} \cdots \mathrm{O}[2.55(2) \AA], \mathrm{O} \cdots \mathrm{C}_{1}$ $[2.73(2) \AA], / \mathrm{C}_{1} \mathrm{OH}-\mathrm{C}_{2} \mathrm{OO}$ group $/ \mathrm{C}_{1}-\mathrm{C}_{2}[1.50(1) \AA], \mathrm{C}_{2}-\mathrm{O}_{\text {carb }}$

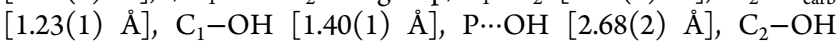
$[2.40(2) \AA], \mathrm{O}_{\text {carb }} \cdots \mathrm{O}_{\text {carb }}[2.21(2) \AA]$, and $\mathrm{C}_{1} \cdots \mathrm{O}_{\text {carb }}[2.36(2) \AA]$. No attempts to locate the $\mathrm{H}$ atoms were made due to the limited quality of the XRPD data. All atoms were isotropically refined. Selected structural data are reported in Table 1. 
For the remaining samples (Na-, K-, and Cs-HPAA), suitable size and quality single crystals were obtained. Measured crystals were handled under inert conditions immersed in perfluoropolyether as protecting oil for manipulation. Suitable crystals were mounted on MiTeGen Micromounts, and these samples were used for data collection. Data were collected on Bruker D8 Venture (Na-HPAA, 298 K), Bruker SMART APEX (K-HPAA, $100 \mathrm{~K}$ ), or Bruker X8 Proteum (Cs-HPAA, $296 \mathrm{~K}$ ) diffractometers. The data were processed with APEX $2^{29}$ program and corrected for absorption using SADABS. ${ }^{30}$ The structures were solved by direct methods, which revealed the position of all non-hydrogen atoms. ${ }^{31}$ These atoms were refined on $F^{2}$ by a fullmatrix least-squares procedure using anisotropic displacement parameters. ${ }^{31}$ All hydrogen atoms were located in difference Fourier maps and included as fixed contributions riding on attached atoms with isotropic thermal displacement parameters $1.2(-\mathrm{C}-\mathrm{H})$ or 1.5 $(-\mathrm{O}-\mathrm{-H})$ times those of the respective atom. In the structure of NaHPAA, the HPAA ligand and the Na2 atom were disordered over two alternative positions and were refined with occupancy factors at a ratio 0.60:0.40. In K-HPAA, hydrogen atoms were not found in the water molecules but were included in the total atomic formula. Crystallographic data and CCDC reference codes of the crystal structures are reported in Table 1.

Thermodiffractometric data for $\mathbf{L i}$-, Na-, and K-HPAA were obtained for the samples loaded in an Anton Paar TTK450 camera under static air. Flow of gases was not employed to avoid sample dehydration prior to the diffraction experiment. Data were collected at different temperature intervals from room temperature to $250{ }^{\circ} \mathrm{C}$ with a heating rate of $5{ }^{\circ} \mathrm{C} \mathrm{min}-1$ and a delay time of $5 \mathrm{~min}$ to ensure thermal stabilization. The data acquisition range was $4-80^{\circ}(2 \theta)$ with a step size of $0.017^{\circ}$. Powder X-ray diffraction patterns were recorded after impedance analysis. Samples were thus mounted onto a zero background sample holders and the surface of the powders leveled using a glass slide. A scan range between $4^{\circ}$ and $60^{\circ}(2 \theta)$ and a $0.03^{\circ}$ step size was employed.

Proton Conductivity Studies. Impedance data were collected on cylindrical pellets $(\sim 5 \mathrm{~mm}$ of diameter and $\sim 1 \mathrm{~mm}$ of thickness) obtained by pressing $\sim 50 \mathrm{mg}$ of sample at $500 \mathrm{MPa}$ for 2 min between porous $\mathrm{C}$ electrodes (Sigracet, GDL $10 \mathrm{BB}$, no Pt). Impedance data were collected using a HP4284A impedance analyzer over the frequency range from $20 \mathrm{~Hz}$ to $1 \mathrm{MHz}$ with an applied voltage of 1 V. All measurements were electronically controlled by the winDETA package of programs. ${ }^{32}$ For Na-HPAA, additional impedance experiments were performed using a FRA Solartron 1260 and porous C electrodes painted with platinized carbon $(20 \% \mathrm{PtC})$. The experiments were run at $98 \%$ relative humidity $(\mathrm{RH})$ and $24{ }^{\circ} \mathrm{C}$, under $5 \% \mathrm{H}_{2}-\mathrm{Ar}$ or $\mathrm{H}_{2}$ gas flows, in the $0.01 \mathrm{~Hz}$ to $1 \mathrm{MHz}$ frequency range and with an ac perturbation of $200 \mathrm{mV}$.

Electrical measurements were recorded in a double-walled, temperature-controlled glass chamber with a gas inlet and outlet. The temperature of the chamber was controlled by a Julabo F32-MA refrigerated/heating circulator from 10 to $24{ }^{\circ} \mathrm{C}$ every $2{ }^{\circ} \mathrm{C}$ with a heating rate of $0.4{ }^{\circ} \mathrm{C} \mathrm{min}{ }^{-1}$ using EasyTEMP software. Samples were equilibrated for $15 \mathrm{~min}$ after each step in temperature, which was measured close to the sample location. The relative $\mathrm{RH}$ was obtained by a continuous flow of water-saturated synthetic air at different temperatures through the cell. Although different equilibration periods were found, all sample pellets were equilibrated at $98 \% \mathrm{RH}$ for $18 \mathrm{~h}$ to ensure a fixed water content of the sample and stable conductivity values. $\mathrm{RH}$ is approximately constant in the measured temperature range, from 10 to $24{ }^{\circ} \mathrm{C}$.

A membrane electrode assembly (MEA) was prepared with a dense pellet of Na-HPAA sandwiched between two nonblocking porous C electrodes. Two circular Pt meshes were used as current collectors. MEA was sealed against the electrochemical setup using a twocomponent epoxy resin. Open circuit voltage (OCV) measurements were carried out with a Keithley 2700 multimeter at $24{ }^{\circ} \mathrm{C}$ and $98 \%$ $\mathrm{RH}$ in both anode and cathode sides, using a flow of $\mathrm{H}_{2}$ as fuel and static air (inside a SPEC SH-222 humidity chamber) as oxidant.

Electronic Circular Dichroism (ECD) and Computational Methods. ECD and UV-vis spectra were recorded on a Jasco 815 spectropolarimeter. Room-temperature spectra from 190 to $600 \mathrm{~nm}$ were collected from a neat solution at $3 \times 10^{-3} \mathrm{M}$ concentration of the sample in $\mathrm{H}_{2} \mathrm{O}$. The following parameters were applied: a scan speed of $200 \mathrm{~nm} \mathrm{~min}{ }^{-1}$ and a spectral bandwidth of $1 \mathrm{~nm}$. The spectrometer was continuously purged with dry $\mathrm{N}_{2}$ gas. The final spectrum was obtained as the average of a minimum of three scans after a blank correction.

The Gaussian '09 package of programs ${ }^{33 a}$ was used for DFT quantum chemical calculations. The Becke's three-parameter (B3) $)^{33 \mathrm{~b}}$ gradient-corrected exchange functional was used, and the nonlocal correlation was provided by the Lee-Yang-Parr (LYP) expressions. ${ }^{33 b, c}$ No structural optimization was performed so as to have the same structure in the calculation as that in the X-ray crystal structure. Spectroscopic features were calculated using the split-valence cc-pvdz basis set. At this level of calculation, the data confirm the existence of ECD bands in the same range of the experimental result. This was checked by comparing ECD at different ab initio methodologies, as 6$31 \mathrm{~g}(\mathrm{~d}), 6-311 \mathrm{~g}(\mathrm{~d}, \mathrm{p})$, or lanl2dz. Electronic excitation energies were obtained by using the time-dependent DFT (TDDFT) formalism ${ }^{33 \mathrm{~d}, \mathrm{e}}$ for which up to 30 low-lying energy states were considered.

\section{RESULTS AND DISCUSSION}

Characterization. FT-IR Spectroscopy. The IR spectra for the alkali metal HPAA compounds, together with that of dry ligand HPAA as a reference, are shown in Figure S-2 (see Supporting Information). These spectra reveal distinctive signals along the series. In the region $3600-3100 \mathrm{~cm}^{-1}$, bands at $3330-3190 \mathrm{~cm}^{-1}$ are indicative of strong hydrogen bonds.

Significantly, the anhydrous compound Cs-HPAA shows a band centered at $3190 \mathrm{~cm}^{-1}$, suggesting an exceptionally strong $\mathrm{H}$-bonding interaction by proton sharing between two basic groups (see below). On the other hand, Na-HPAA also shows, additionally to $\mathrm{H}$-bonded water, a signal at $3525 \mathrm{~cm}^{-1}$ characteristic of coordinated water weakly interacting by $\mathrm{H}$ bonding.

In the $2000-1350 \mathrm{~cm}^{-1}$ range, several asymmetric and symmetric $\nu\left(\mathrm{COO}^{-}\right)$bands are observed. The asymmetric $\nu(\mathrm{C}=\mathrm{O})_{\text {asym }}$ vibrations appear in the region $1577-1630 \mathrm{~cm}^{-1}$, whereas the symmetric $\nu(\mathrm{C}-\mathrm{O})_{\text {sym }}$ stretches are located in the region 1453-1372 $\mathrm{cm}^{-1}$. However, Cs-HPAA shows broad bands at 1820 and $1660 \mathrm{~cm}^{-1}$, which are very near to those of $\nu(\mathrm{COOH})$ of the free acid. The phosphonate group signals appear in the region $890-1200 \mathrm{~cm}^{-1}, \mathrm{P}-\mathrm{O}-$ and $\mathrm{P}=\mathrm{O}$ stretches at $896-1110 \mathrm{~cm}^{-1}$, and antisymmetric stretch of the $-\mathrm{PO}_{3}$ at $1060-1162 \mathrm{~cm}^{-1}$. The variation of the positions and intensities of these bands are indicative of the diversity of binding modes of the phosphonate moiety to the metal ions. All solids, except Li-HPAA, also show a characteristic band of $\mathrm{P}-\mathrm{OH}$ groups at $905-940 \mathrm{~cm}^{-1}$, which are also detected by the overtones at 2800 and $2300 \mathrm{~cm}^{-1}$.

Description of Crystal Structures. Li-HPAA, $\mathrm{Li}_{3}(\mathrm{OOCCH}$ $\left.\left.(\mathrm{OH}) \mathrm{PO}_{3}\right)\left(\mathrm{H}_{2} \mathrm{O}\right)_{4}\right] \cdot \mathrm{H}_{2} \mathrm{O}$. The high crystallinity of Li-HPAA allowed successful structure solution and Rietveld refinement. The observed and calculated X-ray powder diffraction patterns are given in Figure 1. The refinement is satisfactory as evidenced by the low $R$-factors (see Table 1 ) and the flatness of the divergence curve; see Figure 1.

Li-HPAA is a 1D coordination polymer, with a fully deprotonated HPAA $^{3-}$ ligand, thus having a Li:HPAA molar ratio of 3:1. Its infinite dimension is better described as a "slab" or a linear "ribbon", not a chain (see Figure 2). Bridging $\mathrm{HPAA}^{3-}$ anions are responsible for the formation of the "slab", which is $14.668 \AA$ wide and $7.950 \AA$ tall. Each HPAA $^{3-}$ anion coordinates to $6 \mathrm{Li}^{+}$cations (Figure 2, upper). It is worth- 


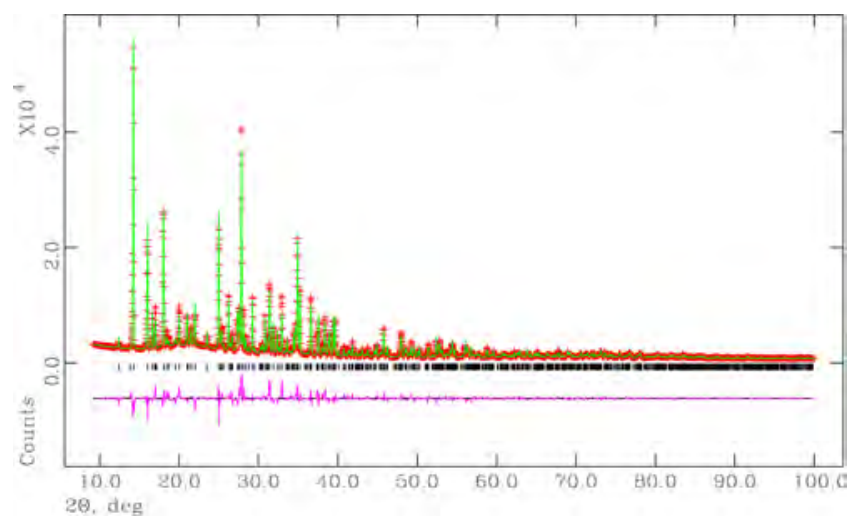

Figure 1. Final observed (crosses), calculated (-), and difference plots for the Rietveld refinement of XRPD data for Li-HPAA.
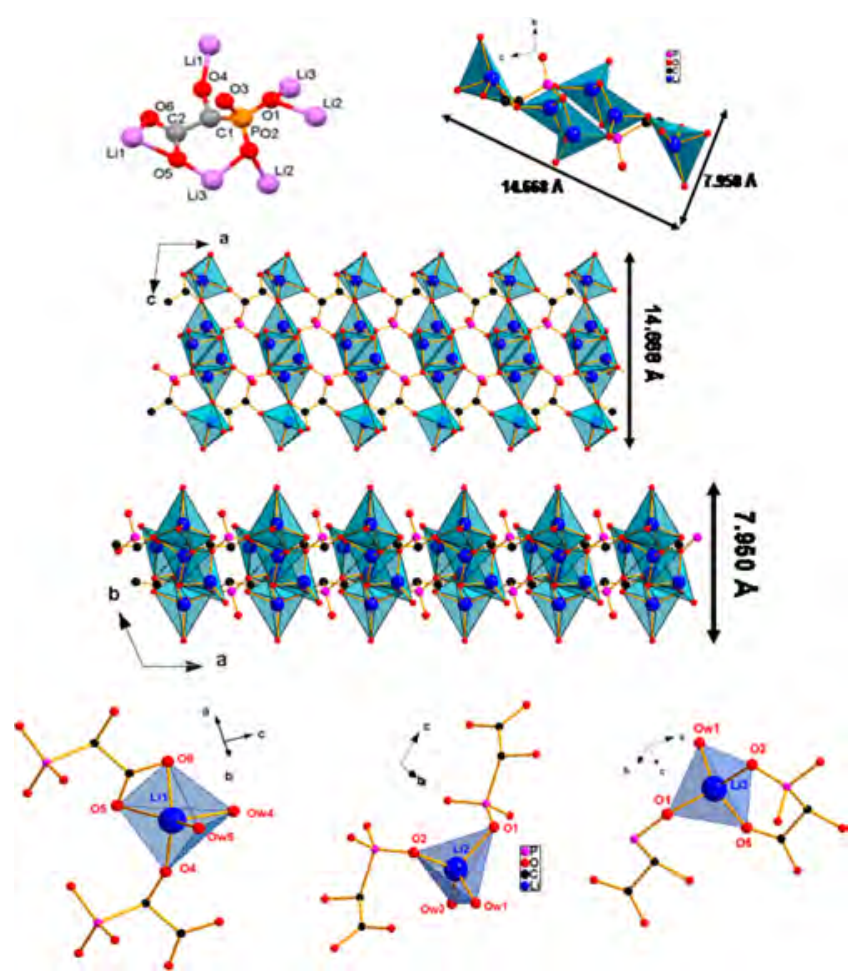

Figure 2. Different views of a portion of the "slab" in the structure of Li-HPAA and the coordination environment of the three Li cations.

noting that of the $6 \mathrm{O}$ atoms of each HPAA ligand, 5 are used, with the exception of one $\mathrm{O}$ atom (O3) of the phosphonate group.

There are three crystallographically independent $\mathrm{Li}^{+}$cations in the structure (Figure 2, bottom). Lil is coordinated by $5 \mathrm{O}$ atoms, in a distorted square pyramidal environment. The five $\mathrm{O}$ atoms originate from the same carboxylate group (O5, O6), from the hydroxyl group (O4) of another HPAA anion, and finally from two coordinated water molecules (Ow4, Ow5). The carboxylate moiety forms a four-membered chelating ring with $\mathrm{Li} 1$. The second lithium cation, $\mathrm{Li} 2$, is coordinated by $4 \mathrm{O}$ atoms in a tetrahedral environment. The four $\mathrm{O}$ atoms originate from two phosphonate groups from two different HPAA anions (O1, O2) and from two water molecules (Ow1, Ow2). No chelating rings are formed around Li2. One of the water molecules (Ow2) acts as a bridge between Li2 and Li3. The third lithium cation, $\mathrm{Li} 3$, is coordinated by $4 \mathrm{O}$ atoms, and possesses tetrahedral geometry as well. The origin of the $\mathrm{O}$ atoms is as follows: O5 comes from a carboxylate group that belongs to a HPAA anion, whose phosphonate group also coordinates to $\mathrm{Li} 3$ (through $\mathrm{O} 2$ ). The coordination environment is completed by a water molecule (Ow1) and a phosphonate $\mathrm{O}$ atom from a different HPAA anion. The corresponding $\mathrm{Li}-\mathrm{O}$ bond distances are given in Table $\mathrm{S}-1$ (see the Supporting Information).

In the structure of Li-HPAA there are five water molecules, four of which coordinate to $\mathrm{Li}$ cations, and one (Ow3) is situated in the lattice. The latter is positioned between the 1D slabs, apparently stabilizing the supramolecular structure through four hydrogen bonds (Supporting Information Figure S-3 and Table S-2).

$\mathrm{Na}-\mathrm{HPAA}, \mathrm{Na}_{2}\left(\mathrm{OOCCH}(\mathrm{OH}) \mathrm{PO}_{3} \mathrm{H}\right)\left(\mathrm{H}_{2} \mathrm{O}\right)_{4}$. The $\mathrm{HPAA}^{2-}$ ligand has its carboxylic group deprotonated and its phosphonic group monodeprotonated, leading to a Na:HPAA molar ratio of $2: 1$. There are two $\mathrm{Na}$ cations ( $\mathrm{Na} 1$ and $\mathrm{Na} 2)$, one $\mathrm{HPAA}^{2-}$ ligand, as well as four lattice water molecules in the asymmetric unit of this structure. Both HPAA ligand and $\mathrm{Na} 2$ atom are disordered over two alternative metal atom positions, $\mathrm{Na2}$ a and $\mathrm{Na} 2 \mathrm{~b}$, with occupancy factors that converged to the ratio 0.60:0.40. The positional disorder is considered to be the result of an enantiomeric excess of $20 \%$ in this structure. The coordination environments of $\mathrm{Na} 1$ and $\mathrm{Na} 2$ are severely distorted octahedra (see Figure 3), as revealed by the $\mathrm{O}-\mathrm{Na}-$ $\mathrm{O}$ angles (the $\mathrm{O}-\mathrm{Na} 1-\mathrm{O}$ angles are in the range 66.7(3)$177.5(3)^{\circ}$ and the $\mathrm{O}-\mathrm{Na} 2-\mathrm{O}$ angles are in the range $77.0(2)-$ $\left.172.3(3)^{\circ}\right)$. For $\mathrm{Na}^{\circ} \mathrm{O}_{6}$ octahedra, two of these $\mathrm{O}$ atoms originate from the carboxylate and the phosphonate groups of a
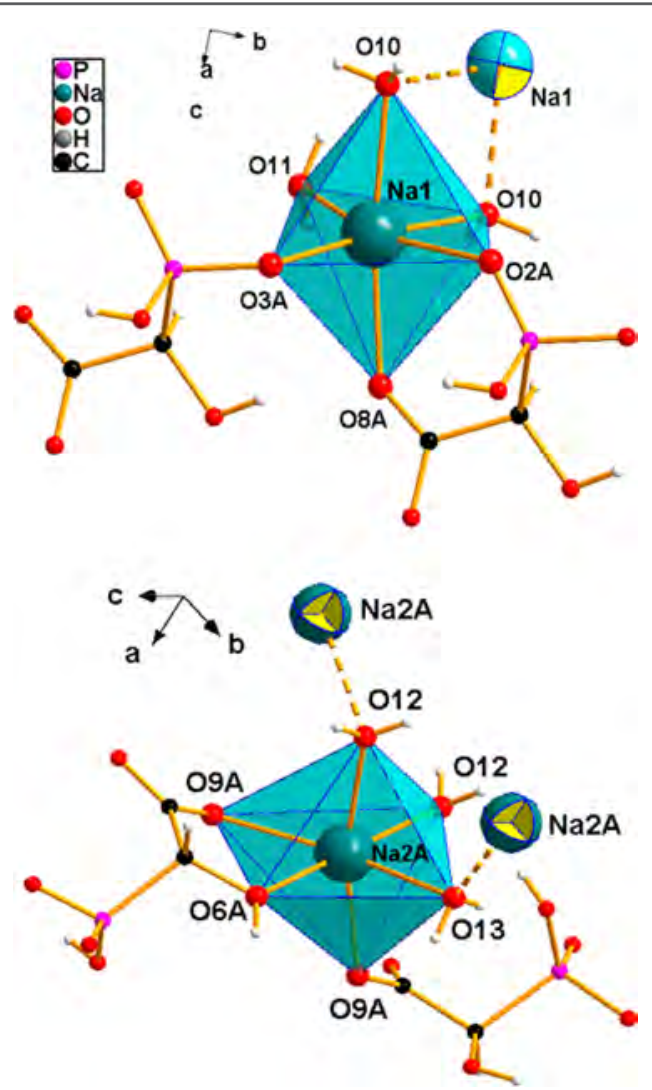

Figure 3. Coordination environments of the two $\mathrm{Na}^{+}$cations in the structure of $\left[\mathrm{Na}_{2}\left(\mathrm{OOCCH}(\mathrm{OH}) \mathrm{PO}_{3} \mathrm{H}\right)\left(\mathrm{H}_{2} \mathrm{O}\right)_{4}\right]$ (Na-HPAA). Bonds that bridge neighboring $\mathrm{Na}^{+}$cations are drawn with dotted lines. 
bidentate $\mathrm{HPAA}^{2-}$ ligand, one phosphonate oxygen from another ligand, and the remaining three $\mathrm{O}$ atoms come from $\mathrm{Na}$-coordinated waters (see Figure 3) $\mathrm{Na} 2$ is also found in a distorted octahedral environment with three $\mathrm{O}$ atoms from water molecules, one from a deprotonated $-\mathrm{COO}^{-}$group of a $\mathrm{HPAA}^{2-}$ ligand, and the remaining two oxygens from the hydroxyl and carboxylate groups of a bidentate ligand. The phosphonate oxygens only coordinate to Nal (see Supporting Information Table S-1).

The bis-deprotonated $\mathrm{HPAA}^{2-}$ coordinates through its phosphonate moiety with two distorted $\mathrm{Na}_{6} \mathrm{O}_{6}$ octahedra, while the $\mathrm{P}-\mathrm{OH}$ group remains noncoordinated. It also uses its carboxylate and hydroxyl groups to bridge two $\mathrm{Na} \mathrm{O}_{6}$ distorted octahedra, and the phosphonate group to coordinate to a $\mathrm{Na}_{2} \mathrm{O}_{6}$ octahedron. This kind of coordination is also found in $\mathrm{Ca}^{2+}$ derivatives, whose structures are composed of a trimeric unit, $\mathrm{Ca}_{3}(\mathrm{HPAA})_{2},{ }^{34}$ as the main building block. To balance charges, two $\mathrm{Nal}$ ions are now equivalent to one $\mathrm{Ca}^{2+}$ ion.

The coordination requirements of the $\mathrm{Na}^{+}$centers and the $\mathrm{HPAA}^{2-}$ ligand generate a 3D framework, shown in Figure 4.
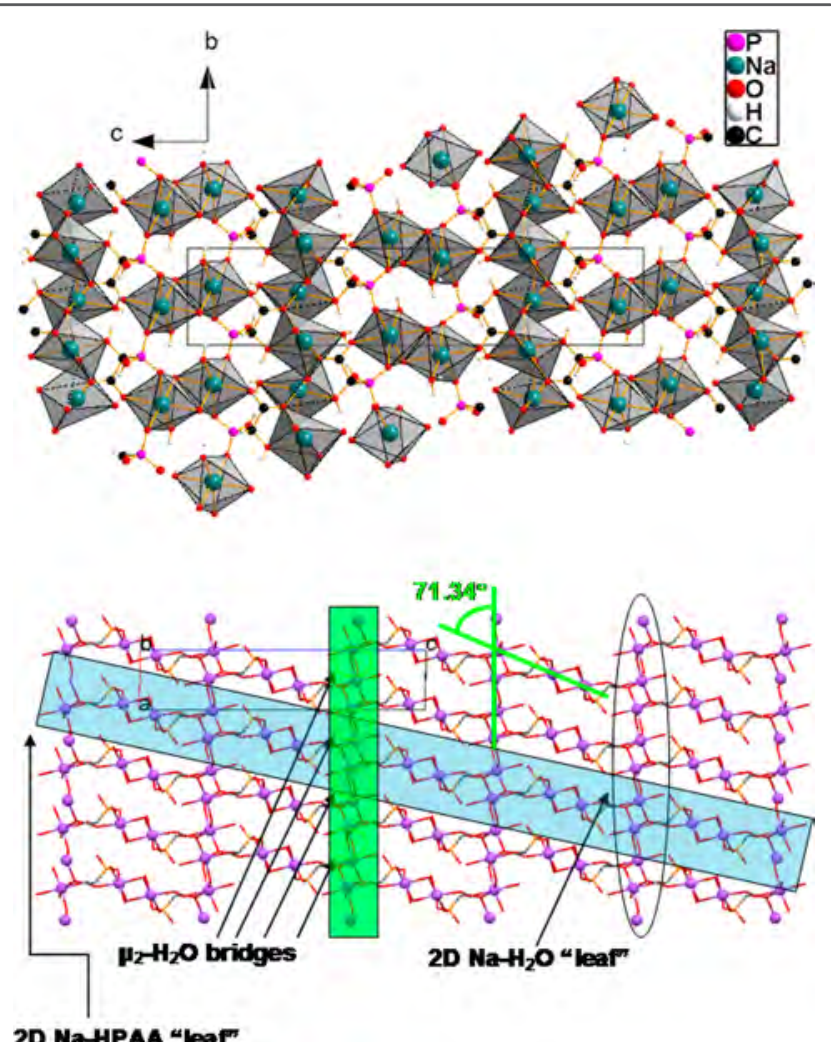

Figure 4. 3D structure views of $\mathrm{Na}_{2}\left(\mathrm{OOCCH}(\mathrm{OH}) \mathrm{PO}_{3} \mathrm{H}\right)\left(\mathrm{H}_{2} \mathrm{O}\right)_{4}$ (Na-HPAA) viewed down the $a$-axis.

There is a five-membered ring formed by the carboxylate oxygen O9, the hydroxyl oxygen $\mathrm{O} 6$, the $\mathrm{Na} 2$ center, and the two carbon atoms $\mathrm{C} 1$ and $\mathrm{C} 2$. A six-membered ring is formed by the second carboxylate oxygen $\mathrm{O} 8$, the deprotonated oxygen $\mathrm{O} 2$ from the phosphonate, a neighboring $\mathrm{Na} 1$ center, and the two carbon atoms $\mathrm{C} 1$ and $\mathrm{C} 2$.

The overall structure of Na-HPAA can be described as a pillared structure. The $2 \mathrm{D}$ layers are formed by the coordination of the $\mathrm{HPAA}^{2-}$ ligand with the $\mathrm{Na}^{+}$cations, which in turn are linked together via water bridges. The latter create a second kind of layers that intersect the first kind of layers at an angle of $71.3^{\circ}$, as shown in Figure 4. The 3D structure of Na-HPAA resembles the topology of a "house of cards".

K-HPAA, $\mathrm{K}_{2}\left(\mathrm{OOCCH}(\mathrm{OH}) \mathrm{PO}_{3} \mathrm{H}\right)\left(\mathrm{H}_{2} \mathrm{O}\right)_{2}$. Its asymmetric unit contains four $\mathrm{K}^{+}$cations, two doubly deprotonated $\mathrm{HPAA}^{2-}$ ligands, and four $\mathrm{K}$-coordinated water molecules. There are no lattice water molecules in the structure. Figure 5 shows the

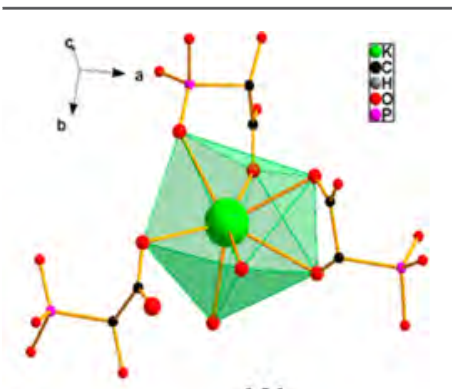

K1

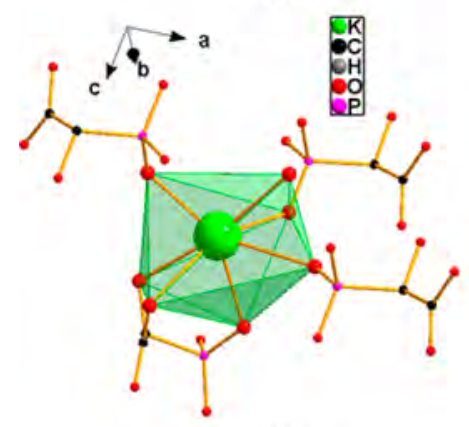

K3

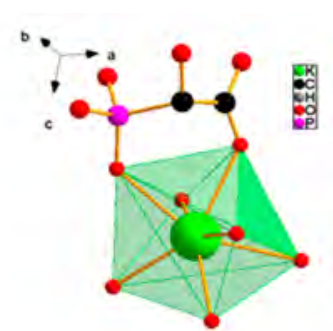

K2

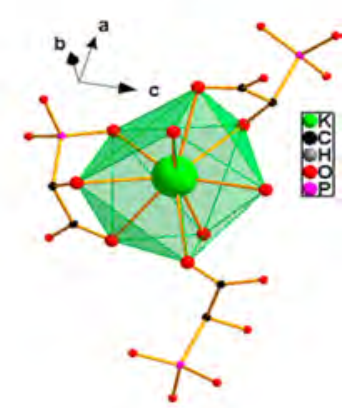

K4
Figure 5. Coordination environments of the four $\mathrm{K}^{+}$cations in the structure of $\mathrm{K}_{2}\left(\mathrm{OOCCH}(\mathrm{OH}) \mathrm{PO}_{3} \mathrm{H}\right)\left(\mathrm{H}_{2} \mathrm{O}\right)_{2}$ (K-HPAA).

coordination environment of the four $\mathrm{K}^{+}$cations. $\mathrm{K} 1$ is 9coordinated with the oxygens coming from the following ligands: 3 carboxylates, 2 phosphonates, 1 hydroxyl, and 3 waters. $\mathrm{K} 2$ is 7 -coordinated ( 1 carboxylate, 5 phosphonate, and 1 water oxygens). $\mathrm{K} 3$ is also 7 -coordinated ( 1 carboxylate, 4 phosphonate, 1 hydroxyl, and 1 water oxygens). K4 is 9coordinated ( 3 carboxylate, 1 phosphonate, 2 hydroxyl, and 3 water oxygens). $\mathrm{K}-\mathrm{O}$ bond distances are listed in the Supporting Information.

The first crystallographically independent $\mathrm{HPAA}^{2-}$ ligand, containing $\mathrm{P} 1$, coordinates through its phosphonate group to two $\mathrm{K}_{10}$, two $\mathrm{K}_{2} \mathrm{O}_{7}$, one $\mathrm{K}_{3} \mathrm{O}_{7}$, and one $\mathrm{K}_{4} \mathrm{O}_{9}$ polyhedra. It

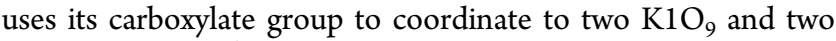
$\mathrm{K}_{4} \mathrm{O}_{9}$ polyhedra (of which $\mathrm{K}_{1} \mathrm{O}_{9}$ and $\mathrm{K}_{4} \mathrm{O}_{9}$ are coordinated by the phosphonate group). Finally, the hydroxyl group coordinates to the $\mathrm{K}_{10}$ and $\mathrm{K}_{4} \mathrm{O}_{9}$ polyhedra. The second crystallographically independent $\mathrm{HPAA}^{2-}$ ligand, containing P2, coordinates through its phosphonate group to three $\mathrm{K}_{3} \mathrm{O}_{7}$ and three $\mathrm{K}_{2} \mathrm{O}_{7}$ polyhedra. It uses its carboxylate group to coordinate to four polyhedra, $\mathrm{K}_{1} \mathrm{O}_{9}, \mathrm{~K}_{2} \mathrm{O}_{7}, \mathrm{~K}_{3} \mathrm{O}_{7}$, and $\mathrm{K}_{4} \mathrm{O}_{9}$. Finally, the hydroxyl group coordinates to $\mathrm{K}_{3} \mathrm{O}_{7}$ and $\mathrm{K}_{4} \mathrm{O}_{9}$ polyhedra.

The structure of K-HPAA is $3 \mathrm{D}$, containing channels along the $a$-axis, whose walls are made of the $\mathrm{K}$-coordinated water molecules. This is shown in Figure 6.

Cs-HPAA, Cs(HOOCCH(OH)PO$\left.{ }_{3} H\right)$. This motif contains a single monodeprotonated $\mathrm{HPAA}^{-}$ligand, and so there is one crystallographically independent $\mathrm{HPAA}^{-}$ligand per one $\mathrm{Cs}^{+}$ 


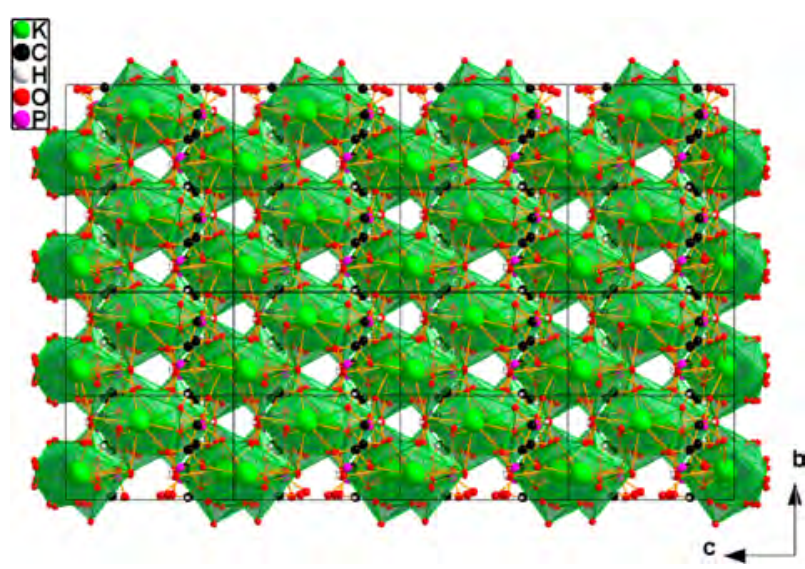

Figure 6. 3D structure of $\mathrm{K}_{2}\left(\mathrm{OOCCH}(\mathrm{OH}) \mathrm{PO}_{3} \mathrm{H}\right)\left(\mathrm{H}_{2} \mathrm{O}\right)_{2}$ (KHPAA), shown along the $a$-axis.

cation. The coordination environments of the $\mathrm{HPAA}^{-}$ligand and $\mathrm{Cs}^{+}$cations are given in Figure 7. Bond distances around the $\mathrm{Cs}^{+}$are given in Supporting Information Table S-1.

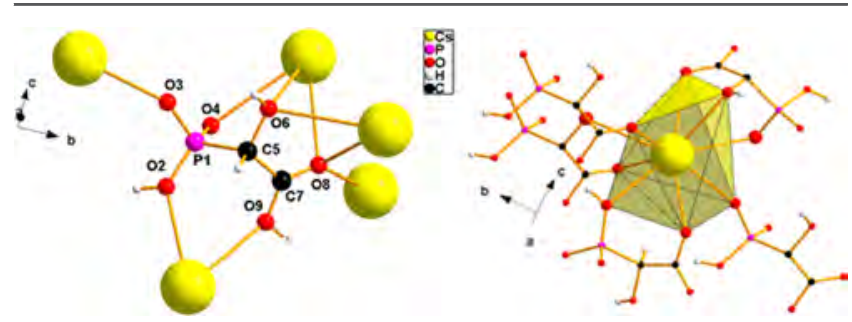

Figure 7. Coordination environment of the HPAA ligand and $\mathrm{Cs}^{+}$ center in the structure of $\mathrm{Cs}\left(\mathrm{HOOCCH}(\mathrm{OH}) \mathrm{PO}_{3} \mathrm{H}\right)$ (Cs-HPAA).

The HPAA ligand has the phosphonate group monodeprotonated $\left(-\mathrm{PO}_{3} \mathrm{H}^{-}\right)$and the carboxy group protonated $(-\mathrm{COOH})$ as confirmed by the FT-IR data. We highlight, however, that the proton of the carboxylic group (O9) is shared with the phosphonate oxygen (O2) from another HPAA ligand (O9-O2 2.485(7) Å, Supporting Information Table S-5). Cs ${ }^{+}$ is 9 -coordinated by oxygen atoms ( 3 from the phosphonate, 4 from carboxylate, and 2 from hydroxyl groups). These originate from four distinct $\mathrm{HPAA}^{-}$ligands. The coordination environment of $\mathrm{Cs}^{+}$can be described as distorted bicapped trigonal antiprism. The $\mathrm{O}-\mathrm{Cs}-\mathrm{O}$ angles range from $\sim 45^{\circ}$ to $\sim 163^{\circ}$. The coordination requirements of $\mathrm{Cs}$ centers create a $3 \mathrm{D}$ structure of Cs-HPAA, which is shown in Figure 8.

Despite the observed trend of increasing ligand denticity toward larger $\mathrm{M}^{+}$ions, a direct relationship between the $\mathrm{M}^{+}$ radius and the average $\mathrm{M}-\mathrm{O}$ bond distance $(\mathrm{M}=$ metal ion $)$ is still maintained (Supporting Information Figure S-4). These observations confirm previous reports on alkaline-earth metal HPAA $^{5 b, 34,35}$ systems and/or alkaline-earth AMP systems. ${ }^{36}$

The complexity of the M-HPAA structures deserves further discussion. The effect of the alkali metal ionic radii is demonstrated not only on the $\mathrm{M}-\mathrm{O}$ bond distances, but also on the coordination number of the metal center. The $\mathrm{Li}^{+}$ cations in the structure of Li-HPAA are either 4-coordinated or 5-coordinated (by two HPAA ligands and one or two water molecules). The structure adopted is 1D "ribbon" or "slab". The $\mathrm{Na}^{+}$ions in the structure of Na-HPAA are 6-coordinated (by two HPAA ligands and three water molecules). The structure adopted is pillared $3 \mathrm{D}$ with bidimensional layers. The

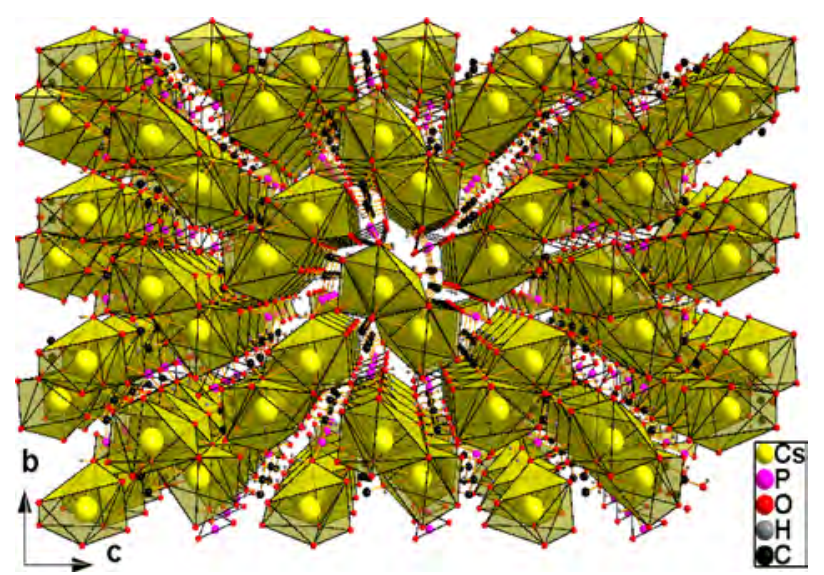

Figure 8. 3D structure of $\mathrm{Cs}\left(\mathrm{HOOCCH}(\mathrm{OH}) \mathrm{PO}_{3} \mathrm{H}\right)$ (Cs-HPAA), shown along the $a$-axis.

$\mathrm{K}^{+}$cations in the 3D structure of K-HPAA are 7-coordinated and 9-coordinated. Finally, the largest cation $\mathrm{Cs}^{+}$is 9coordinated in the 3D structure of Cs-HPAA (four HPAA ligands, but no water molecules).

It is remarkable that from the racemic mixture of $R, S$-HPAA used in the synthesis, both $S$ and $R$ isomers end up in the crystal structures of M-HPAA solids except for Cs-HPAA, which incorporates only the $S$ (but not the $R$ ) isomer. Thus, LiHPAA nests both isomers aligned parallel to the $a$-axis (see Figure 9). In Na-HPAA and K-HPAA compounds, both enantiomers of the ligand are incorporated as well.

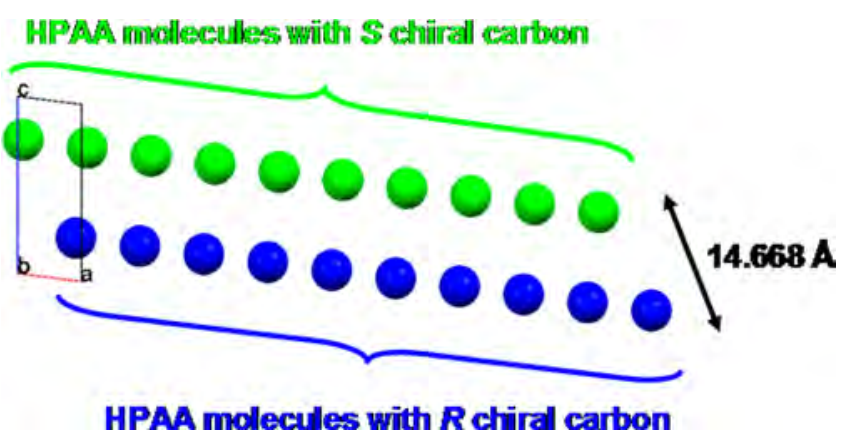

Figure 9. Parallel alignment of the $R$ and $S$ HPAA isomers within a single "slab" in the structure of Li-HPAA (10 unit cells). $R$ isomers are shown in blue, and $S$ isomers are in green.

The bulk chirality of Cs-HPAA, which crystallized in a chiral space group and contains only the S-HPAA ligand, has been investigated in solution by ECD. The racemic $R, S$-HPAA acid and a sample of Cs-HPAA, prepared by fast precipitation in $96 \%$ ethanol, were used as references. As can be seen in Figure 10, the ECD spectrum of the solution of Cs-HPAA, obtained by slow crystallization, exhibits a negative dichroic signal at 210 $\mathrm{nm}$ that is absent in the reference samples. In addition, the spectrum of Cs-HPAA calculated by using crystallographic data without further optimization (Figure 10 and Figure S-5, Supporting Information) agrees well with that obtained experimentally, leading a negative signal between 200 and $300 \mathrm{~nm}$, which confirms an enantiomeric excess in the sample prepared by slow crystallization.

Cs-HPAA, therefore, constitutes a striking example of spontaneous enantiomeric enrichment from a racemic mixture, as racemic conglomerates are usually obtained when achiral 


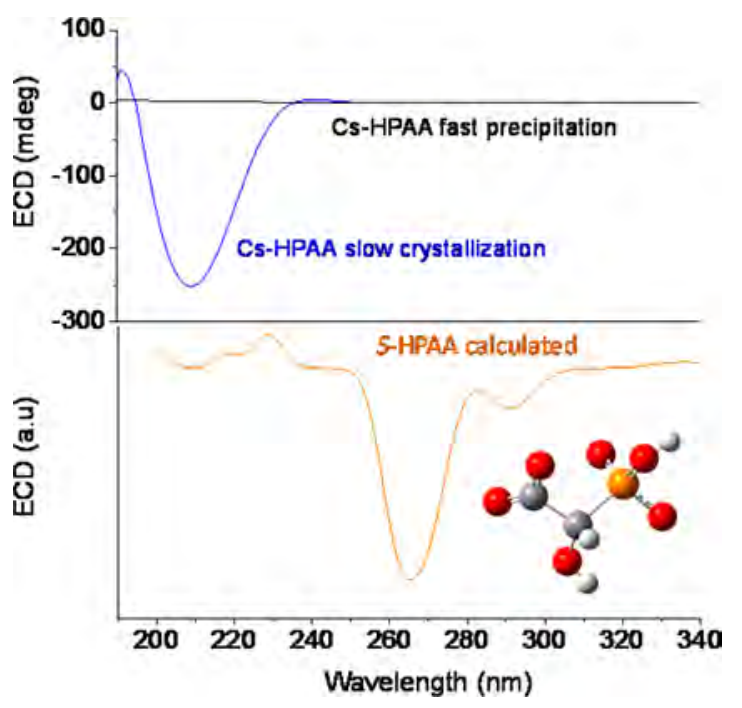

Figure 10. ECD spectra for Cs-HPAA prepared by slow crystallization (blue line), fast precipitation (black line), and the calculated dichroic spectrum for the $S$-HPAA enantiomer.

and/or asymmetric phosphonate ligands are employed as starting materials. ${ }^{37,38}$

Thermogravimetric Studies. As inferred from the above crystallographic study, water plays different important cohesion roles in the structures of M-HPAA $(\mathrm{M}=\mathrm{Li}, \mathrm{Na}$, and $\mathrm{K})$ compounds. Thus, the structural stability and, hence, some important water-related properties should be strongly influenced by the structural positioning of the water molecules. Figure 11 shows the TGA curves for M-HPAA $(\mathrm{M}=\mathrm{Li}, \mathrm{Na}$,

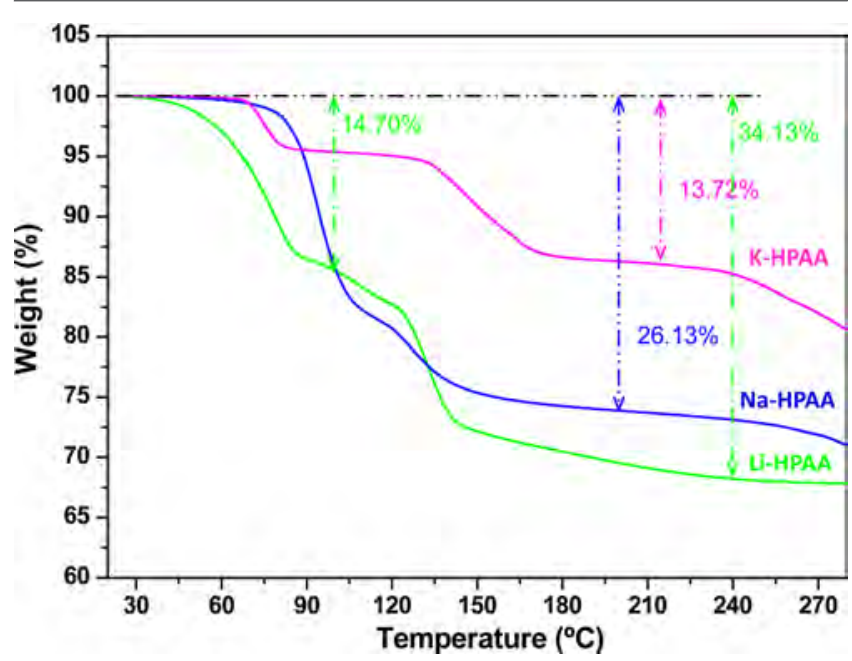

Figure 11. TGA curves for the M-HPAA $(\mathrm{M}=\mathrm{Li}, \mathrm{Na}$, and $\mathrm{K})$ compounds.

and $\mathrm{K}$ ). The anhydrous Cs-HPAA exhibits a nondescript weight loss from ligand decomposition (at $T>220^{\circ} \mathrm{C}$ ) and is not included in Figure 11.

A stepwise weight loss is observed for $\mathrm{Li}-$, $\mathrm{Na}$-, and $\mathrm{K}$ derivatives. Li-HPAA starts to lose water at a lower temperature than the others, attributed mainly to its $1 \mathrm{D}$ architecture. During the first stage, from room temperature to $100{ }^{\circ} \mathrm{C}$, a weight loss of $14.70 \%$ is observed, which fits well with the removal of two water molecules (calculated 13.65\%). From these, one originates from the weakly retained lattice water and the other one, most likely, from a rearrangement of the coordination spheres of $\mathrm{Li}^{+}$ions. Three additional water molecules (measured overall loss $34.13 \%$, calculated $31.72 \%$ ) are lost in the second stage, up to $T=240{ }^{\circ} \mathrm{C}$. A further temperature increase leads to decomposition of the material, which is complete above $700{ }^{\circ} \mathrm{C}$ (not shown). K-HPAA loses its four coordinating water molecules by heating from $\sim 80$ to $180{ }^{\circ} \mathrm{C}$ (measured loss $13.72 \%$, calculated 13.43\%), while decomposition starts at $\sim 240{ }^{\circ} \mathrm{C}$. Na-HPAA retains its water content even more tightly, starting to lose weight at $\sim 90{ }^{\circ} \mathrm{C}$. This behavior is associated with the stronger interaction of water in the pillared framework, as suggested by the FT-IR spectrum (see previous discussion). The removal of the four coordinating water molecules in Na-HPAA is extended up to $200{ }^{\circ} \mathrm{C}$ (measured loss 26.13\%, calculated 26.48\%), while further decomposition of the material starts at $T>270{ }^{\circ} \mathrm{C}$.

As revealed by thermodiffraction (Supporting Information Figure S-6), the loss of structural water upon heating implies a progressive amorphization of the M-HPAA $(\mathrm{M}=\mathrm{Li}, \mathrm{Na}$, and K) solids. Only Li-HPAA showed a transient new semicrystalline phase, formed at $100{ }^{\circ} \mathrm{C}$. Crystalline phases were not recovered on cooling at room temperature for any studied hybrid compound.

Proton Conduction. Generating effective proton transport pathways in solids, to design new proton conductors for potential applications in ionic devices is now becoming a matter of increasing interest. Given that $\mathrm{H}$-bond networks is a distinctive structural feature of metal phosphonates, a study of the proton conductivity behavior has been undertaken for the hybrid alkali metal phosphonate series. Impedance spectra at different temperatures and $98 \%$ relative humidity $(\mathrm{RH})$ are shown in Figure 12.

When a M-HPAA pellet is exposed to $98 \% \mathrm{RH}$ atmosphere, a spike is observed that has an associated capacitance of $\sim 1 \mu \mathrm{F}$. Because the spike is inclined to the $Z^{\prime}$ axis by $\sim 70^{\circ}$, it indicates a partial-blocking electrode response that allows limited diffusion; therefore, the conducting species must be ionic

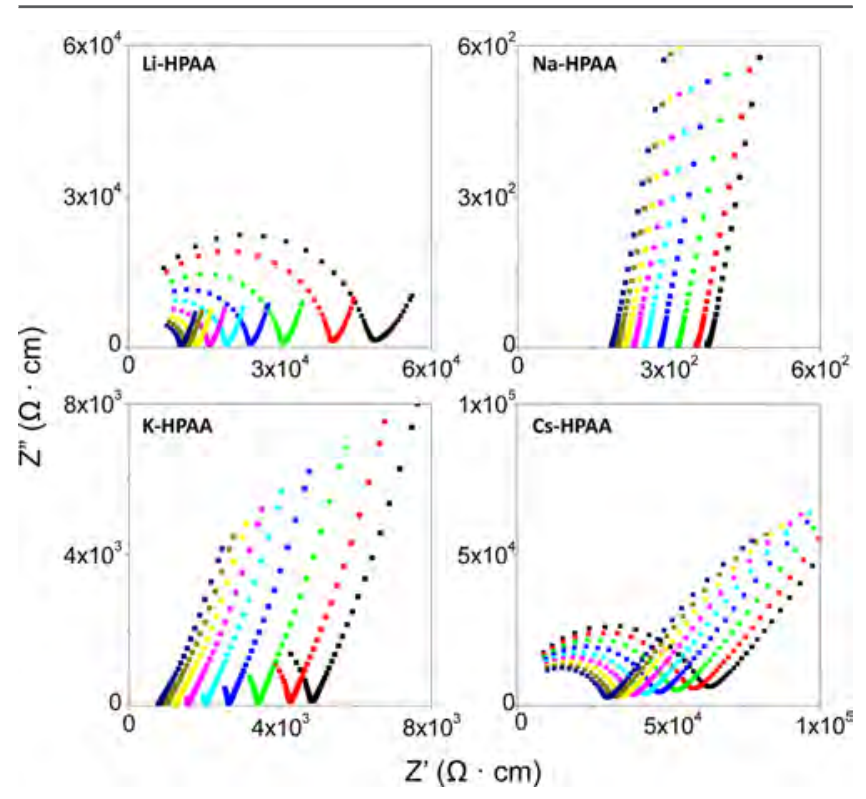

Figure 12. Plots of complex impedance plane for the as-synthesized compounds at $98 \%$ relative humidity: $10{ }^{\circ} \mathrm{C}$ (black), $11^{\circ} \mathrm{C}$ (red), 12 ${ }^{\circ} \mathrm{C}$ (green), $14{ }^{\circ} \mathrm{C}$ (blue), $16{ }^{\circ} \mathrm{C}$ (cyan), $18{ }^{\circ} \mathrm{C}$ (magenta), $20{ }^{\circ} \mathrm{C}$ (yellow), $22{ }^{\circ} \mathrm{C}$ (dark yellow), and $24{ }^{\circ} \mathrm{C}$ (navy). 
(i.e., $\mathrm{H}^{+}$ions). The total pellet resistance $\left(R_{\mathrm{T}}\right)$ was calculated from the intercept of the spike or, alternatively, from the arc (low frequency end) on the $Z^{\prime}$ axis. The overall pellet conductivities for M-HPAA series, in traditional Arrhenius format, are given in Figure 13.

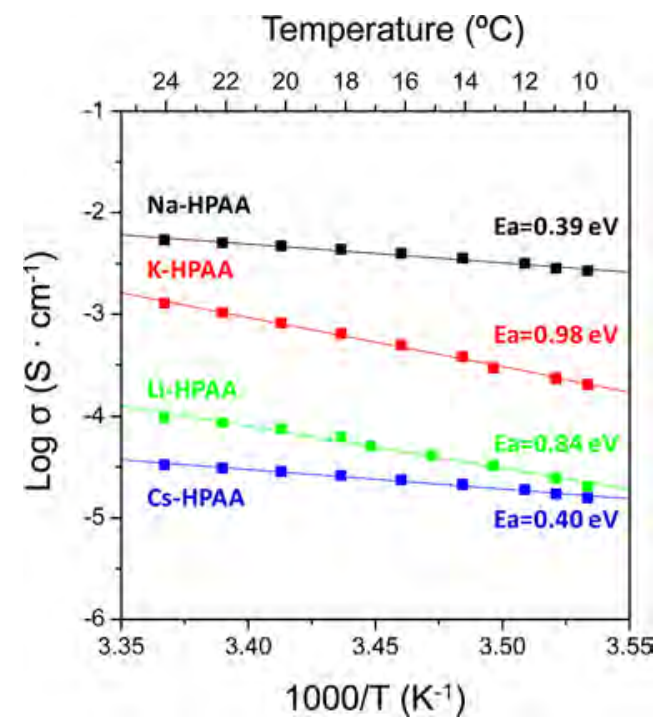

Figure 13. Plot of $\log \sigma$ versus $1000 / T$ for the four "as-synthesized" M-HPAA ( $\mathrm{M}=\mathrm{Li}, \mathrm{Na}, \mathrm{K}$, and $\mathrm{Cs})$ compounds.

The conductivity, at $24{ }^{\circ} \mathrm{C}$, varies in the series from $3.5 \times$ $10^{-5}$ to $5.6 \times 10^{-3} \mathrm{~S} \mathrm{~cm}^{-1}$, for Cs- and $\mathrm{Na}$-derivatives, respectively. The latter value is higher than those of highly hydrated Ln-HPAA derivatives ${ }^{6 \mathrm{~d}}$ and similar to those of tetraphosphonates of $\mathrm{Ca},{ }^{6 e} \mathrm{Mg},{ }^{39}$ or $\mathrm{Ln}^{6 c}$ as well as some nonphosphonate MOF materials. An example is $\left(\mathrm{NH}_{4}\right)(\mathrm{adp})$ $\left[\mathrm{Zn}_{2}(\mathrm{ox})_{3}\right] \cdot n \mathrm{H}_{2} \mathrm{O}^{3 \mathrm{~b}}(n=3$, adp = adipic acid, ox $=$ oxalate $)$ whose proton conductivity was found in the range $1.6 \times 10^{-3}$ to $8 \times 10^{-3} \mathrm{~S} \mathrm{~cm}^{-1}$ at $25^{\circ} \mathrm{C}$.

The possibility of alkali ion conduction was ruled out by using, for the highest conductive material (Na-HPAA), nonblocking electrodes to protons, under $5 \% \mathrm{H}_{2}-\mathrm{Ar}$ and $\mathrm{H}_{2}$ gas flows. Figure 14 shows only one semicircle with capacitance

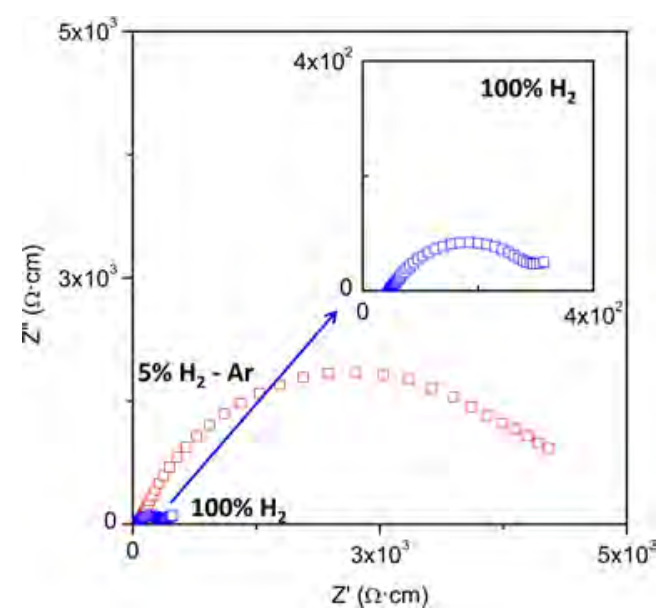

Figure 14. Plots of complex impedance plane for the as-synthesized Na-HPAA equilibrated at $24{ }^{\circ} \mathrm{C}$ and $98 \% \mathrm{RH}$, in flowing $5 \% \mathrm{H}_{2}-\mathrm{Ar}$ and $\mathrm{H}_{2}$. Measurements were performed using $\mathrm{Pt}-\mathrm{C}$ gas diffusion electrodes. values due to electrode polarization between 3 and $0.1 \mathrm{mF}$ $\mathrm{cm}^{-1}$, for $5 \% \mathrm{H}_{2}-\mathrm{Ar}$ and $\mathrm{H}_{2}$ gas flows, respectively. The absence of the spike in the data indicates that the material shows a purely resistive behavior, and, therefore, it is exclusively a proton conductor. Moreover, it is also observed that the polarization resistance is greatly improved in pure $\mathrm{H}_{2}$ with values 1 order of magnitude lower than in $5 \% \mathrm{H}_{2}-\mathrm{Ar}$. This behavior is explained by diffusion limitations when dilute $\mathrm{H}_{2}$ is used.

Pelletized samples were analyzed by TGA (Supporting Information Figures S7-S10) and PXRD (Supporting Information Figures S11-S14) immediately after impedance analyses to notice possible structural and/or water content changes. Except for Na-HPAA, no significant weight gain was observed. The water gain for Na-HPAA is $~ 31 \%$ (weight loss about $34.3 \%$, $5.5 \mathrm{~mol} \mathrm{H}_{2} \mathrm{O}$ per formula, up to $200{ }^{\circ} \mathrm{C}$ ). However, the corresponding PXRD pattern did not reveal significant changes, as compared to the initial sample (see Supporting Information Figure S12). The pattern containing a few additional low intensity diffraction peaks could be indexed in a related cell with doubled $a$ parameter, according to the Le Bail fit (Supporting Information Figure S15). This behavior can be explained taking into account that the pillared structure of the $\mathrm{Na}$ derivative can still host more water molecules with hardly any modification of the basic pillared framework.

The water adsorption-desorption isotherm of this compound is also consistent with that behavior. As seen in Supporting Information Figure S16, Na-HPAA hardly adsorbs water up to about $90 \% \mathrm{RH}$, the total amount not exceeding 1 $\mathrm{H}_{2} \mathrm{O}$ molecule per formula unit. The lack of reversibility (hysteresis) in the sorption/desorption profile indicates that the moisture is absorbed inside the structure rather than being adsorbed on the surface of the material. Furthermore, the stability of this material was preliminarily checked as candidate for PEMFCs. As can be seen in Supporting Information Figure $\mathrm{S} 17$, open circuit voltage (OCV) measurements at $24{ }^{\circ} \mathrm{C}$ and $98 \% \mathrm{RH}$, carried out using a flow of $\mathrm{H}_{2}$ as fuel and static air as oxidant, revealed that a constant voltage value of $\sim 0.6 \mathrm{~V}$ was attained. The low value measured, as compared to the thermodynamic voltage at $24{ }^{\circ} \mathrm{C}$ and 1 atm pressure $(1.18$ $\mathrm{V})$, may be caused by voltage drops, that is, reaction between $\mathrm{Pt}$ surface and $\mathrm{O}_{2}$ resulting in a mixed cathode potential or $\mathrm{H}_{2}$ crossover from anode to cathode reducing the $\mathrm{O}_{2}$ concentration. ${ }^{40}$ Further studies are needed to clear up this point that are beyond the scope of this Article.

K-HPAA, on the contrary, did not exhibit changes in water content (Supporting Information Figure S9) during the impedance study $(>18 \mathrm{~h})$, and thus showed reproducible conductivity values, albeit the sample tends to be deliquescent at $T>20{ }^{\circ} \mathrm{C}$ in a high humidity atmosphere. For all other compounds, this characteristic was not observed, at least within $48 \mathrm{~h}$ of experiment duration.

Comparing the conductivity pattern of the higher dimensionality solids $\left(\mathrm{Na}^{+}, \mathrm{K}^{+}\right.$, and $\left.\mathrm{Cs}^{+}\right)$, the obtained values are consistent with the presence of acidic groups and an increasing content of water molecules, acting as proton carriers into the framework. The presence of mobile proton carriers, that is, lattice water molecules, should further enhance the proton transfer pathways, as observed for Na-HPAA. In addition, structural disorder in this framework may contribute to conductivity enhancement. The presence of extended hydrogen-bonding networks in these solids contributes to define different proton transfer pathways (Supporting Information 
Tables S2-S5). Despite the anhydrous nature of Cs-HPAA, it still exhibits a residual conductivity, within the range for many MOFs. ${ }^{6,41,42}$ In this case, short proton transport pathways exist in the structure, due to strong $\mathrm{H}$-bond interactions between neighboring $-\mathrm{P}-\mathrm{OH}$ and $-\mathrm{COOH}$ groups, as well as the presence of equidistant shared protons between phosphonate and carboxylate groups (see Supporting Information Table S5). K-HPAA has intermediate characteristics between Na- and Cs-derivatives, and thus an intermediate conductivity value is measured $\left(1.3 \times 10^{-3} \mathrm{~S} \mathrm{~cm}^{-1}\right)$. The lack of lattice water in the latter structure makes the proton conduction more difficult, which occurs by a vehicular mechanism $\left(E_{\mathrm{a}}>0.5 \mathrm{eV}\right)$, probably through a water ligand exchange. In variance with this behavior, the proton conduction in Na- and Cs-derivatives occurs by a Grotthuss mechanism, according to the lower activation energies found in such cases (see Figure 13). The conductivity of Li-HPAA, $1.1 \times 10^{-4} \mathrm{~S} \mathrm{~cm}^{-1}$, is low as compared to that of the $\mathrm{Na}$ - and K-derivatives, mainly due to the absence of acidic groups and the low mobility of strongly coordinated water in the former. Such a value is, however, very close to those reported for other $1 \mathrm{D}$ divalent tetraphosphonates, in which a vehicular mechanism is also implied. ${ }^{42}$ Significantly, the protonation degree of the ligand, which increases from $\mathrm{Li}$, through $\mathrm{Na}$ and $\mathrm{K}$, to $\mathrm{Cs}$ is not directly correlated to the conductivity values. However, the activation energy decreases when the protonation degree increases in samples with the lowest water content (Li-HPAA and Cs-HPAA samples).

\section{CONCLUSIONS}

Alkali-metal ions exhibit a rich coordination chemistry with the ligand hydroxyphosphonoacetic acid (HPAA), showing a straightforward variation of the coordination environment according to the cation size. Hence, $\mathrm{Li}^{+}$is 4-coordinated and 5-coordinated while $\mathrm{Cs}^{+}$is exclusively 9-coordinated. The $\mathrm{M}^{+}$ coordination requirements are satisfied by tuning ligand denticity and also by the presence of water for the lighter ions. $\left[\mathrm{Cs}\left(\mathrm{HOOCCH}(\mathrm{OH}) \mathrm{PO}_{3} \mathrm{H}\right)\right]$ (Cs-HPAA) was the only anhydrous compound in the series. All structures notwithstanding show the presence of strong hydrogen-bond networks, as demonstrated by FTIR and structural analyses. As a result of this coordinative pattern and connectivity, a progressive increase of the solid dimensionality, from $1 \mathrm{D}$ to $3 \mathrm{D}$, is demonstrated. In addition, all solids exhibit variable proton conductivity, strongly dependent on the structural role of water molecules and the hydrogen-bonding networks established. In particular, the Na-derivative containing both lattice and bound water and having a certain structural disorder has been demonstrated to exhibit a high proton conductivity of $5.6 \times$ $10^{-3} \mathrm{~S} \mathrm{~cm}^{-1}$. Furthermore, a full study of this material revealed no alkali ion conduction and high stability under PEMFC working conditions.

Another relevant structural feature of alkali-metal HPAA compounds is the size-dependent enrichment in the $S$ enantiomer upon crystallization, which is particularly evident in the case of Cs-HPAA. This preference for one enantiomer is believed to be related to the strong hydrogen-bonding interactions required for structural stabilization. Last, from a synthetic point of view, Cs-HPAA may be viewed as a useful starting material and a source of $S$-HPAA for further metalHPAA MOF syntheses that will yield chiral MOF products incorporating only the $S$ enantiomer.

\section{ASSOCIATED CONTENT}

\section{Supporting Information}

Figure S-1: Powder X-ray diffraction patterns for Cs-HPAA. Figure S-2: FT-IR of $\mathrm{HOOCCH}(\mathrm{OH}) \mathrm{PO}_{3} \mathrm{H}_{2}$ and $\mathrm{M}(\mathrm{I})$-HPAA $(\mathrm{M}=\mathrm{Li}, \mathrm{Na}, \mathrm{K}$ and $\mathrm{Cs})$. Figure S-3: Hydrogen bonds in the structure of $\left[\mathrm{Li}_{3}\left(\mathrm{OOCCH}(\mathrm{OH}) \mathrm{PO}_{3}\right)\left(\mathrm{H}_{2} \mathrm{O}\right)_{4}\right] \cdot \mathrm{H}_{2} \mathrm{O}$. Figure $\mathrm{S}$ 4: Dependence of the $\mathrm{M}-\mathrm{O}$ (phosphonate), $\mathrm{M}-\mathrm{O}$ (carboxy), and $\mathrm{M}-\mathrm{O}$ (hydroxyl) bond distances on alkali-metal ionic radii. Figure S5: ECD spectra calculated for $\mathrm{Cs}(\mathrm{HOOCCH}(\mathrm{OH})$ $\left.\mathrm{PO}_{3} \mathrm{H}\right)$ using different $\mathrm{ab}$ initio basis sets. Figure S-6: Thermodiffraction patterns for M(I)-HPAA ( $M=\mathrm{Li}, \mathrm{Na}$, and K). Figures S-7-S-10: TG curves for M(I)-HPAA $(M=L i$, $\mathrm{Na}, \mathrm{K}$, and Cs) before and after impedance analyses. Figure $\mathrm{S}$ 11-S-14: PXRD patterns for M(I)-HPAA ( $\mathrm{M}=\mathrm{Li}, \mathrm{Na}, \mathrm{K}$, and Cs) before and after impedance analyses. Figure S-15: Le Bail fit for Na-HPAA after impedance analysis. Figure S-16: Water vapor isotherm for Na-HPAA. Figure S-17: Open circuit voltage curve of Na-HPAA. Table S-1: Selected bond distances for M(I)-HPAA ( $\mathrm{M}=\mathrm{Li}, \mathrm{Na}, \mathrm{K}$, and Cs). Table S-2: H-bond interactions $(\AA)$ for Li-HPAA. Table S-3: H-bond interactions (A) for Na-HPAA. Table S-4: H-bond interactions $(\AA)$ for KHPAA. Table S-5: H-bond interactions $(\AA)$ for Cs-HPAA. CIF files for Li-HPAA, $\left[\mathrm{Li}_{3}\left(\mathrm{OOCCH}(\mathrm{OH}) \mathrm{PO}_{3}\right)\left(\mathrm{H}_{2} \mathrm{O}\right)_{4}\right] \cdot \mathrm{H}_{2} \mathrm{O}$, NaHPAA, $\mathrm{Na}_{2}\left(\mathrm{OOCCH}(\mathrm{OH}) \mathrm{PO}_{3} \mathrm{H}\right)\left(\mathrm{H}_{2} \mathrm{O}\right)_{4}$, K-HPAA, $\mathrm{K}_{2}\left(\mathrm{OOCCH}(\mathrm{OH}) \mathrm{PO}_{3} \mathrm{H}\right)\left(\mathrm{H}_{2} \mathrm{O}\right)_{2}$, and Cs-HPAA, Cs$\left(\mathrm{HOOCCH}(\mathrm{OH}) \mathrm{PO}_{3} \mathrm{H}\right)$. This material is available free of charge via the Internet at http://pubs.acs.org.

\section{AUTHOR INFORMATION}

\section{Corresponding Authors}

*E-mail: aurelio@uma.es.

*E-mail: demadis@chemistry.uoc.gr.

\section{Author Contributions}

This is part of the Ph.D. of Montse Bazaga-García. The manuscript was written through contributions of all authors. All authors have given approval to the final version of the manuscript.

\section{Funding}

The work at UoC was supported by grants from the Research Committee of the University of Crete, ELKE (Grant no. KA 3806). The work at UMA was funded by MAT2010-15175 and MAT2013-41836-R research grants (Spain), which are cofunded by FEDER and by Junta de Andalucia (Spain) FQM-1656. The project "Factoria de Crystallización, CONSOLIDER INGENIO-2010” provided X-ray structural facilities for this work.

\section{Notes}

The authors declare no competing financial interest.

\section{ACKNOWLEDGMENTS}

We thank Prof. Francisco J. Ramírez and Prof. Juan T. López Navarrete (Departamento de Química Física, Universidad de Málaga) for fruitful discussions on ECD and computational methods. We thank Prof. Joaquín Silvestre-Albero (Depatamento de Química Inorgánica, Universidad de Alicante, Spain) for water vapor isotherms.

\section{REFERENCES}

(1) (a) Special thematic issue on Metal Organic Frameworks. Chem. Rev. 2012, 112, 673-1268. (b) Special thematic issue on Hybrid Materials. Chem. Soc. Rev. 2011, 40, 453-1152. (c) Themed issue on Metal-Organic Frameworks. Chem. Soc. Rev. 2009, 38, 1201. 
(d) McDonald, T. M.; Lee, W. R.; Mason, J. A.; Wiers, B. M.; Hong, C. S.; Long, J. R. J. Am. Chem. Soc. 2012, 134, 7056-7065. (e) Cirujano, F. G.; Llabrés i Xamena, F. X.; Corma, A. Dalton Trans. 2012, 41, 4249. (f) Nasalevich, M. A.; van der Veen, M.; Kapteijn, F.; Gascon, J. CrystEngComm 2014, 16, 4919-4926. (g) He, Y.; Zhou, W.; Yildirimbd, T.; Chen, B. Energy Environ. Sci. 2013, 6, $2735-2744$

(2) (a) Morozan, A.; Jaouen, F. Energy Environ. Sci. 2012, 5, 92699290. (b) Furukawa, H.; Cordova, K. E.; O’Keeffe, M.; Yaghi, O. M. Science 2013, 341, 1230444. (c) Ren, Y.; Chia, G. H.; Gao, Z. Nanotoday 2013, 8, 577-597. (d) Li, S.-L.; Xu, Q. Energy Environ. Sci. 2013, 6, 1656-1683. (e) Hurd, J. A.; Vaidhyanathan, R.; Thangadurai, V.; Ratcliffe, C. I.; Moudrakovski, I. L.; Shimizu, G. K. H. Nat. Chem. 2009, 1, 705-710. (f) Liang, X.; Zhang, F.; Feng, W.; Zou, X.; Zhao, C.; Na, H.; Liu, C.; Sun, F.; Zhu, G. Chem. Sci. 2013, 4, 983-992.

(3) (a) Inukai, M.; Horike, S.; Chen, W.; Umeyama, D.; Itakurad, T.; Kitagawa, S. J. Mater. Chem. A 2014, 2, 10404-10409. (b) Sadakiyo, M.; Yamada, T.; Honda, K.; Matsui, H.; Kitagawa, H. J. Am. Chem. Soc. 2014, 136, 7701-7707. (c) Paenasi, F. J. Phys. Chem. C 2013, 117, 19508-19516. (d) Sahoo, S. C.; Kundu, T.; Banerjee, R. J. Am. Chem. Soc. 2011, 133, 17950-17958. (e) Horike, S.; Umeyama, D.; Kitagawa, S. Acc. Chem. Res. 2013, 46, 2376-2384. (f) Sadakiyo, M.; Okawa, H.; Shigematsu, A.; Ohba, M.; Yamada, T.; Kitagawa. J. Am. Chem. Soc. 2012, 134, 5472-5475. (g) Shigematsu, A.; Yamada, T.; Kitagawa, K. J. Am. Chem. Soc. 2011, 133, 2034-2036. (h) Taylor, J. M.; Dawson, K. W.; Shimizu, G. K. H. J. Am. Chem. Soc. 2013, 135, 1193-1196.

(4) Kim, S.; Dawson, K. W.; Gelfand, B. S.; Taylor, J. M.; Shimizu, G. K. H. J. Am. Chem. Soc. 2013, 135, 963-966. (b) Ponomareva, V. G.; Kovalenko, K. A.; Chupakhin, A. P.; Dybtsev, D. N.; Shutova, E. S.; Fedin, V. P. J. Am. Chem. Soc. 2012, 134, 15640-15643.

(5) (a) Shimizu, G. K. H.; Taylor, J. M.; Kim, S. Science 2013, 341, 354-355. (b) Metal Phosphonate Chemistry: From Synthesis to Applications; Clearfield, A., Demadis, K. D., Eds.; The Royal Society of Chemistry: London, 2012.

(6) (a) Taylor, J. M.; Mah, R. K.; Moudrakovski, I. L.; Ratcliffe, C. I.; Vaidhyanathan, R.; Shimizu, G. K. H. J. Am. Chem. Soc. 2010, 132, 14055-14057. (b) Sadakiyo, M.; Yamada, T.; Kitagawa, H. J. Am. Chem. Soc. 2009, 131, 9906-9907. (c) Colodrero, R. M. P.; OliveraPastor, P.; Losilla, E. R.; Aranda, M. A. G.; Leon-Reina, L.; Papadaki, M.; McKinlay, A. C.; Morris, R. E.; Demadis, K. D.; Cabeza, A. Dalton Trans. 2012, 41, 4045-4051. (d) Colodrero, R. M. P.; Papathanasiou, K. E.; Stavgianoudaki, N.; Olivera-Pastor, P.; Losilla, E. R.; Aranda, M. A. G.; León-Reina, L.; Sanz, J.; Sobrados, I.; Choquesillo-Lazarte, D.; García-Ruiz, J. M.; Atienzar, P.; Rey, F.; Demadis, K. D.; Cabeza, A. Chem. Mater. 2012, 24, 3780-3792. (e) Bazaga-García, M.; Colodrero, R. M. P.; Papadaki, M.; Garczarek, P.; Zoń, J.; Olivera-Pastor, P.; Losilla, E. R.; León-Reina, L.; Aranda, M. A. G.; Choquesillo-Lazarte, D.; Demadis, K. D.; Cabeza, A. J. Am. Chem. Soc. 2014, 136, 57315739. (f) Pardo, E.; Train, C.; Gontard, G.; Boubekeur, K.; Fabelo, O.; Liu, H.; Dkhil, B.; Lloret, F.; Nakagawa, K.; Tokoro, H.; Ohkoshi, S.; Verdaguer, M. J. Am. Chem. Soc. 2011, 133, 15328-15331. (g) Umeyama, D.; Horike, S.; Inukai, M.; Hijikata, Y.; Kitagawa, S. Angew. Chem., Int. Ed. 2011, 50, 11706-11709.

(7) Lis, T. Acta Crystallogr. 1997, C53, 28-42.

(8) Cheng, C.-Y.; Lin, K.-J. Acta Crystallogr. 2006, C62, m363-m365.

(9) Kinnibrugh, T. L.; Garcia, N.; Clearfield, A. J. Solid State Chem. 2012, 187, 149-158.

(10) Mermer, A.; Starynowicz, P. Acta Crystallogr. 2011, B67, 399408.

(11) Deacon, G. B.; Greenhill, N. B.; Junk, P. C.; Wiecko, M. J. Coord. Chem. 2011, 64, 179-185.

(12) (a) Eddaoudi, M.; Kim, J.; Rosi, N.; Vodak, D.; Wachter, J.; O'Keeffe, M.; Yaghi, O. M. Science 2002, 295, 469-472. (b) Kitagawa, S.; Kitaura, R.; Noro, S. Angew. Chem., Int. Ed. 2004, 43, 2334-2375.

(13) (a) Han, S. S.; Goddard, W. A. J. Am. Chem. Soc. 2007, 129, 8422. (b) Mulfort, K. L.; Hupp, J. T. J. Am. Chem. Soc. 2007, 129, 9604. (c) Mulfort, K. L.; Farha, O. K.; Stern, C. L.; Sarjeant, A. A.; Hupp, J. T. J. Am. Chem. Soc. 2009, 131, 3866. (d) Yang, S. H.; Lin, X.;
Blake, A. J.; Walker, G. S.; Hubberstey, P.; Champness, N. R.; Schroder, M. Nat. Chem. 2009, 1, 487-493.

(14) (a) Tarascon, J. M.; Armand, M. Nature 2001, 414, 359-367. (b) Armand, M.; Tarascon, J. M. Nature 2008, 451, 652-657.

(15) (a) Gadjourova, Z.; Andreev, Y. G.; Tunstall, D. P.; Bruce, P. G. Nature 2001, 412, 520-523. (b) Stoeva, Z.; Martin-Litas, I.; Staunton, E.; Andreev, Y. G.; Bruce, P. G. J. Am. Chem. Soc. 2003, 125, 46194626. (c) Zhang, C. H.; Gamble, S.; Ainsworth, D.; Slawin, A. M. Z.; Andreev, Y. G.; Bruce, P. G. Nat. Mater. 2009, 8, 580-584.

(16) Martinez-Tapia, H. S.; Cabeza, A.; Bruque, S.; Pertierra, P.; Garcia-Granda, S.; Aranda, M. A. G. J. Solid State Chem. 2000, 151, 122-129.

(17) Ayi, A. A.; Burrows, A. D.; Mahon, M. F.; Pop, V. M. J. Chem. Crystallogr. 2011, 41, 1165-1168.

(18) Gossman, W. L.; Wilson, S. R.; Oldfield, E. Acta Crystallogr. 2002, C58, m599-m600.

(19) Vega, D.; Baggio, R.; Garland, M. T. Acta Crystallogr. 1996, C52, 2198-2201.

(20) Vega, D.; Fernaandez, D.; Ellena, J. A. Acta Crystallogr. 2002, C58, $\mathrm{m} 77-\mathrm{m} 80$.

(21) Vega, D.; Baggio, R.; Piro, O. Acta Crystallogr. 1998, C54, 324327

(22) Zhou, W.; Bondarenko, A. S.; Boukamp, B. A.; Bouwmeester, H. J. M. Solid State Ionics 2008, 179, 380-384.

(23) Vijayakumar, M.; Traer, J. W.; Britten, J. F.; Goward, G. R. J. Phys. Chem. C 2008, 112, 5221-5231.

(24) Boultif, A.; Louer, D. J. Appl. Crystallogr. 2004, 37, 724-731.

(25) Rius, J.; Vallcorba, O.; Peral, I.; Frontera, C.; Miravitlles, C. DAjust Software: Pattern Matching, Space Group Determination and Intensity Extraction from Powder Diffraction Data; Instituto de Ciencias de los Materiales de Barcelona (CSIC): Spain, 2011.

(26) Rius, J. Acta Crystallogr. 2011, A67, 63.

(27) Rietveld, H. M. J. Appl. Crystallogr. 1969, 2, 65-71.

(28) Larson, A. C.; Von Dreele, R. B. General Structure Analysis System (GSAS); Los Alamos National Laboratory Report LAUR 86748, 2004.

(29) Bruker. APEX2 Software, V.2013.6; Bruker AXS Inc.: Madison, WI.

(30) Sheldrick, G. M. SADABS, Program for Empirical Absorption Correction of Area Detector Data; University of Göttingen: Germany, 2009.

(31) Sheldrick, G. M. Acta Crystallogr., Sect. A: Found. Crystallogr. 2008, A64, 112.

(32) winDETA; Novocontrol GmbH: Hundsangen, Germany, 1995.

(33) (a) Frisch, M. J.; Trucks, G. W.; Schlegel, H. B.; Scuseria, G. E.; Robb, M. A.; Cheeseman, J. R.; Scalmani, G.; Barone, V.; Mennucci, B.; Petersson, G. A.; Nakatsuji, H.; Caricato, M.; Li, X.; Hratchian, H. P.; Izmaylov, A. F.; Bloino, J.; Zheng, G.; Sonnenberg, J. L.; Hada, M.; Ehara, M.; Toyota, K.; Fukuda, R.; Hasegawa, J.; Ishida, M.; Nakajima, T.; Honda, Y.; Kitao, O.; Nakai, H.; Vreven, T.; Montgomery, J. A., Jr.; Peralta, J. E.; Ogliaro, F.; Bearpark, M.; Heyd, J. J.; Brothers, E.; Kudin, K. N.; Staroverov, V. N.; Kobayashi, R.; Normand, J.; Raghavachari, K.; Rendell, A.; Burant, J. C.; Iyengar, S. S.; Tomasi, J.; Cossi, M.; Rega, N.; Millam, N. J.; Klene, M.; Knox, J. E.; Cross, J. B.; Bakken, V.; Adamo, C.; Jaramillo, J.; Gomperts, R.; Stratmann, R. E.; Yazyev, O.; Austin, A. J.; Cammi, R.; Pomelli, C.; Ochterski, J. W.; Martin, R. L.; Morokuma, K.; Zakrzewski, V. G.; Voth, G. A.; Salvador, P.; Dannenberg, J. J.; Dapprich, S.; Daniels, A. D.; Farkas, O.; Foresman, J. B.; Ortiz, J. V.; Cioslowski, J.; Fox, D. J. Gaussian 09, revision A.2; Gaussian, Inc.: Wallingford, CT, 2009. (b) Becke, A. D. J. Chem. Phys. 1993, 98, 5648-5652. (c) Stephens, P. J.; Devlin, F. J.; Chabalowski, C. F.; Frisch, M. J. J. Phys. Chem. 1994, 98, 1162311627. (d) Runge, E.; Gross, E. K. U. Phys. Rev. Lett. 1984, 52, 9971000. (e) Gross, E. K. U.; Kohn, W. Adv. Quantum Chem. 1990, 21, 255-294.

(34) (a) Demadis, K. D.; Papadaki, M.; Cisarova, I. ACS Appl. Mater. Interface 2010, 2, 1814-1816. (b) Colodrero, R. M. P.; Cabeza, A.; Olivera-Pastor, P.; Rius, J.; Choquesillo-Lazarte, D.; García-Ruiz, J. M.; 
Papadaki, M.; Demadis, K. D.; Aranda, M. A. G. Cryst. Growth Des. 2011, 11, 1713-1722.

(35) (a) Demadis, K. D.; Papadaki, M.; Raptis, R. G.; Zhao, H. J. Solid State Chem. 2008, 181, 679-683. (b) Demadis, K. D.; Papadaki, M.; Raptis, R. G.; Zhao, H. Chem. Mater. 2008, 20, 4835-4846.

(c) Colodrero, R. M. P.; Olivera-Pastor, P.; Cabeza, A.; Papadaki, M.; Demadis, K. D.; Aranda, M. A. G. Inorg. Chem. 2010, 49, 761-768.

(36) Demadis, K. D.; Katarachia, S. D. Phosphorus, Sulfur Silicon 2004, 179, 627-648. Demadis, K. D.; Katarachia, S. D.; Koutmos, M. Inorg. Chem. Commun. 2005, 8, 254-258. Demadis, K. D.; Katarachia, S. D.; Zhao, H.; Raptis, R. G.; Baran, P. Cryst. Growth Des. 2006, 6, $836-838$.

(37) Hou, S.-Z.; Cao, D.-K.; Li, Y.-Z.; Zheng, L.-M. Inorg. Chem. 2008, 47, 10211-10213.

(38) (a) Fredoueil, F.; Evain, M.; Massiot, D.; Bujoli-Doeuff, M.; Bujoli, B. J. Mater. Chem. 2001, 11, 1106. (b) Liu, X.-G.; Bao, S.-S.; Li, Y.-Z.; Zheng, L.-M. Inorg. Chem. 2008, 47, 5525. (c) Mao, J.-G.; Wang, Z.-K.; Clearfield, A. Inorg. Chem. 2002, 41, 6106.

(39) Colodrero, R. M. P.; Olivera-Pastor, P.; Losilla, E. R.; Hernández-Alonso, D.; Aranda, M. A. G.; León-Reina, R. J.; Moreau, B.; Demadis, K. D.; Villemin, D.; Palomino, M.; Rey, F.; Cabeza, A. Inorg. Chem. 2012, 51, 7689-7698.

(40) Zhang, J. L.; Tang, Y. H.; Song, C. J.; Zhang, J. J.; Wang, H. J. J. Power Sources 2006, 163, 532-537.

(41) (a) Liang, X.; Zhang, F.; Zhao, H.; Ye, W.; Long, L.; Zhu, G. Chem. Commun. 2014, 50, 6513-6516. (b) Sahoo, S. C.; Kundu, T.; Banerjee, R. J. Am. Chem. Soc. 2011, 133, 17950. (c) Constatino, F.; Donnadio, M.; Casciola, M. Inorg. Chem. 2012, 51, 6992. (d) Mallick, A.; Kundua, T.; Banerjee, R. Chem. Commun. 2012, 48, 8829-8831.

(42) (a) Colodrero, R. M. P.; Angeli, G. K.; Bazaga-Garcia, M.; Olivera-Pastor, P.; Villemin, D.; Losilla, E. R.; Martos, E. Q.; Hix, G. B.; Aranda, M. A. G.; Demadis, K. D.; Cabeza, A. Inorg. Chem. 2013, 52, 8770-8783. (b) Feyand, M.; Seidler, C. F.; Deiter, C.; Rothkirch, A.; Lieb, A.; Wark, M.; Stock, N. Dalton Trans. 2013, 42, 8761-8770. 